\title{
Use of electronic nose technology to measure soil microbial activity through biogenic volatile organic compounds and gases release
}

\author{
Fabrizio De Cesare ${ }^{\mathrm{a}, \mathrm{b}, *}$, Elena Di Mattia ${ }^{\mathrm{c}}$, Simone Pantalei ${ }^{\mathrm{b}}$, Emiliano Zampetti ${ }^{\mathrm{b}}$, \\ Vittorio Vinciguerra ${ }^{a}$, Francesco Canganella ${ }^{a}$, Antonella Macagnano ${ }^{b}$ \\ ${ }^{a}$ Department for Innovation in Biological, Agro-food and Forest Systems, University of Tuscia, 01100 Viterbo, Italy \\ ${ }^{\mathrm{b}}$ Institute for Microelectronics and Microsystems, National Research Council, Via Fosso del Cavaliere 100, 00133 Rome, Italy \\ ${ }^{\mathrm{c}}$ Department of Agriculture, Forests, Nature and Energy, University of Tuscia, Via S. Camillo De Lellis, 01100 Viterbo, Italy
}

\section{A R T I C L E I N F O}

\section{Article history:}

Received 17 October 2010

Received in revised form

29 May 2011

Accepted 13 June 2011

Available online 6 July 2011

Keywords:

Microbial activity

Enzymes

Respiration

Electronic nose

Microbial biomass

SIR

Pseudomonas fluorescens

\begin{abstract}
A B S T R A C T
Gas and volatile organic compounds (VOCs) release in soil is known to be linked to microbial activity and can differently affect the life of organisms in soil. Electronic noses (E-noses) are sensing devices composed of sensor arrays able to measure and monitor gases and VOCs in air. This is the first report on the use of such a sensing device to measure specifically microbial activity in soil. In the present study, $\gamma$-irradiated sterilised soil was inoculated with Pseudomonas fluorescens. To be sure for a rapid microbial growth and activity, two pulses of nutrient solution with organic and inorganic C, N, P and S sources were added to soil and the resulting microcosms were incubated for $23 \mathrm{~d}$. During the incubation, respiration and enzyme activities of acid phosphatase, $\beta$-glucosidase, fluorescein diacetate hydrolase and protease, were measured, and microbial growth as global biomass of vital cells based on substrate-induced respiration $\left(\mathrm{SIR}-\mathrm{C}_{\mathrm{mic}}\right)$ and enumeration of viable and culturable cells by means of dilution plate counts (CFU) were also monitored. Concurrently, VOCs and/or gas evolution in the headspace of the soil microcosms were measured through the E-nose, upon their adsorption on quartz crystal microbalances (QCMs) comprising the sensory device. The E-nose typically generated an odorant image (olfactory fingerprint) representative of the analysed samples (soils) and resulting from the concurrent perception of all or most of the analytes in headspace, as it commonly happens when several selective but not specific sensors are used together (array). The basic hypothesis of this study was that different soil ecosystems expressing distinct microbial metabolic activities, tested through respiration and enzyme activities, might generate different olfactory fingerprints in headspace. Furthermore, the possibility to detect several substances at the same time, released from the soil ecosystems, possibly deriving from both abiotic and biotic (microbial metabolism) processes provides an "odorant image" representative of the whole ecosystem under study. The E-nose here used succeeded in discriminating between inoculated and non-inoculated ecosystems and in distinguishing different metabolic and growth phases of the inoculated bacteria during incubation. Specifically, E-nose responses were proved highly and significantly correlated with all hydrolytic activities linked to the mobilisation of nutrients from soil organic matter and their cycling, with $\mathrm{CO}_{2}$ fluxes (respiration and presumed heterotrophic fixation) and with $P$. fluorescens population dynamics during exponential, stationary and starvation phases measured by SIR- $C_{\text {mic }}$ and CFUs. Interestingly, the E-nose successfully detected soil microbial activity stimulated by nutrient supply, even though none of the catalytic activities tested directly produced VOCs and/or gases. The E-nose technology was then proved able to supply a real holistic image of microbial activity in the entire gnotobiotic and axenic soil ecosystems.
\end{abstract}

(c) 2011 Elsevier Ltd. All rights reserved.

\section{Introduction}

The production of volatiles by microorganisms has been well known for several decades. In soil specifically, atmosphere greatly

\footnotetext{
* Corresponding author. Tel.: +39 0761 357338; fax: +39 0761357242

E-mail address: decesare@unitus.it (F. De Cesare).
}

differs from the outer atmosphere for the presence of volatile organic compounds (VOCs) and gases mainly resulting from metabolic activity of soil organisms (mostly microorganisms) (Conrad, 1996), hence their classification as biogenic substances. The degradation of substrates for nutrient and energy supply through oxidative and fermentative metabolism and the production of organic acids and other by-products through intermediary 
metabolism by microorganisms are all processes that bring about the release of biogenic VOCs and gases in soil (Sheppard and Loyd, 2002). These substances include a wide range of chemical compounds: alcohols, aldehydes, aromatics, esters, ethers, hydrocarbons, ketones, nitriles, terpenses, sulfides (Leff and Fierer, 2008; McNeal and Herbert 2009), that influence both microbial metabolism (Smolander et al., 2006) and interactions among microorganisms (e.g. antimicrobial antagonists) as well as with other organisms (Fernando et al., 2005). It has been well-documented in the last decades that most biogenic volatile compounds are speciesspecific and that the patterns of volatile compounds produced by microorganisms result from specific physiological traits, growth phases (exponential, stationary, etc.) and growth conditions (Fernando et al., 2005; Kai et al., 2009; Thorn et al., 2011).

Several techniques are available for the measurement and analysis of gases and VOCs in environments. Of these, electronic noses (E-noses) are devices made up of sensor arrays able to monitor atmosphere or headspace of samples. The ability of E-noses to perceive odorant analytes is based on several principles, such as gravimetry, optics, electrical conductivity, redoxability and electrical field influence, and depends on the properties of the sensing materials used as coatings, which may change after interaction with volatile analytes (Grate and Abraham, 1991). In the case of E-noses based on quartz crystal microbalances (QCMs), the sensory measurement is based on the transduction of gravimetric variations into electrical signals that occur as a result of changes in quartz oscillation frequency upon the adsorption of analytes onto sensitive films coating the quartz (Lucklum et al., 1991). The primary advantage of the use of E-noses is the presence of an array of sensors coated with differentially and partially specific, despite selective, sensitive films, i.e. which can interact with single analytes belonging to the same chemical class, but not highly specific for a single substance, only, and which can also interact with substances belonging to other chemical classes (cross-selectivity), despite to a lower extent (overlapping responses of different sensors) (Pearce et al., 2003). The pool of E-nose responses to a mixture of analytes is then commonly processed through pattern recognition analyses (Principal Component Analysis - PCA, Partial Least Squares - PLS, etc.) to obtain an odorant chemical fingerprint (olfactory fingerprint) typical of the analysed sample (Pearce et al., 2003), similarly to what occurs in mammalian perception, thus the name 'electronic nose' (Persaud et al., 1996). E-noses have also been used to detect specifically biogenic VOCs produced by microorganisms in several environments (Gibson et al., 1997; McEntegart et al., 2000). However, to date, the applications of E-noses in soil have been very few. They include: i) the measurement of ammonium content after its conversion into gaseous ammonia in alkaline conditions from $\mathrm{KCl}$ soil extracts and after the E-nose (8 sensor array) calibration with suitable ammonium concentrations in the same experimental conditions (De Cesare et al., 2009); ii) the detection of pollutants (gasoline) in laboratory experiments (spiked soil slurries) and in the field, through the preliminary E-nose ( 7 sensor array) calibration with benzene, toluene, ethyl benzene and xylene standards and the following detection of volatiles from the mixture and the field (Kurup et al., 2006); iii) the degradation of pollutant(phenanthrene) spiked soil by resident microorganisms through the prior calibration of the E-nose ( 8 sensor array) with standard concentrations of phenanthrene and then measuring the response to volatiles released in headspaces compared to the chromatographic profile detected by a solid phase microextraction analysed through a gas spectrometer coupled to a mass spectrometer (SPME/GC-MS) (De Cesare et al., 2008); iv) the assessment of the influence of soil type, soil environmental conditions and nutrient addition on soil volatile production patterns obtained through the exposure of an E-nose (14 sensor array) to headspace of soil samples at different environmental conditions (Bastos and Magan, 2007). In the last case, however, no assessment of the real involvement of microbial populations and their relationship to E-nose responses was performed, upon the lack of suitable controls.

Typically, soil microbial activity is measured through several parameters (Nannipieri et al., 1990) that are used as indicators of soil quality and health, fertility, disease suppression and environmental changes and have been extensively reviewed in the last decades and mainly involve respiration and soil enzymes (Dick, 1997; He et al., 2003; Nannipieri et al., 2002; Pankhurst, 1994). Among soil enzymes, hydrolytic enzymes are commonly used by soil microbial populations to mobilise elements (C, N, P, S) from soil organic matter (SOM) in order to support their survival and proliferation. Phosphatase, $\beta$-glucosidase, arylsulfatase and protease activities are the hydrolytic enzymes mostly responsible for the mobilisation and acquisition of such nutritive elements and then for their biogeochemical cycling (Shaw and Burns, 2006). Fluorescein diacetate hydrolase activity, instead, is commonly used as a parameter to measure total activity of bacteria and fungi (Schnürer and Rosswall, 1982). The variations in the activity of these enzymes are then reasonably related to conditions in soil ecosystems where nutrients become limiting and also physiological modifications can affect bacteria population. Although several attempts have been made to describe the metabolic activity in soil ecosystems, by using single or multiple indices collecting several biochemical and microbiological parameters, it is still difficult, however, to find out a parameter or an index able to satisfactorily match such a need of soil scientists. The use of the E-nose technology might supply a further contribution to solve this problem.

The present study was then planned to verify the capability of an E-nose of measuring the microbial activity in soil ecosystems, by comparing its responses to the measures of biochemical and microbiological parameters commonly used for such detection in soils, e.g. respiration and hydrolytic enzyme activities (Taylor et al., 2002; Renella et al., 2007). The rationale for this study was that different soil ecosystems with distinct microbial metabolic activities, expressed through respiration and enzyme activities, might result in different olfactory fingerprints. Then, this study was specifically focused on the achievement of 3 objectives: i) to fill the gap due to the likely objections arising from the possible emissions of VOCs and even gases from soil components and the added substrates upon specific environmental conditions used during the experiments; ii) to relate more specifically the E-nose responses to the microbial activity measurable in soil samples, both as a consequence of point i) and mainly because proper and typically accepted methods for detecting microbial activity in soil were used as references; iii) to supply an easy and less time-consuming tool for microbial activity detection in soil. However, the products released through hydrolytic transformations of SOM only sometimes are VOCs and/or gases. By contrast, the E-nose is an electronic instrument capable of detecting VOCs and/or gases in atmosphere or headspace. Since the object of the present study is the comparison of these two different approaches to detect microbial metabolic activity, the possible relationship between the measures resulting from the two kinds of methodologies could not be direct and it needs to be evaluated. Notwithstanding, it is common to find out in soil studies that hydrolytic activities are highly correlated to respiration (Margesin et al., 2000; de la Paz Jimenez et al., 2002), so that $\mathrm{CO}_{2}$ is related to enzymatic activities although the latters have no direct connection with such a gas production. This event can be reasonably explained by suggesting that the hydrolytic products may be further degraded through other metabolic pathways involving other enzymes (despite not specifically tested) up to mineralisation, as well as it happens in the well known process of "priming effect" when nutrients become limiting and where the 
extra hydrolytic activities are related to the extra $\mathrm{CO}_{2}$ release (Blagodatskaya and Kuzyakov, 2008).

\section{Materials and methods}

To test the hypothesis reported in the previous section, the experimental plan was designed to set up soil microcosms consisting of sterilised soil inoculated or not (control) with soil bacteria and added with nutrients in order to ensure the survival of the microbial population from the planktonic condition of the inoculum to the sessile condition of the soil ecosystem and its growth, as well as to stimulate its metabolic activity. Respiration, enzyme activities of acid phosphatase (APase), $\beta$-glucosidase (GLUase), fluorescein diacetate hydrolase (FDAHase), arylsulfatase (ASase) and protease (PROase), as biochemical parameters, and microbial growth as global biomass of vital cells based on induced respiration (SIR-C mic) and enumeration of viable and culturable cells (CFU), as microbiological parameters, were tested in soil microcosms. The latter microbiological parameters were chosen because they specifically detect really living and metabolically active (non-resting) microbial biomass, and are then more suitable to assess the physiological responses of soil microorganisms when subjected to environmental changes (Di Mattia et al., 2002; Bååth et al., 2005): SIR- $C_{m i c}$ measures, in fact, the respiratory response of only glucoseresponsive and active microorganisms, while CFU measure the population of culturable cells that Bååth et al. (2005) demonstrated to be characterised by high specific activity. Hence, these parameters were preferred to those that detect the whole microbial biomass including dead cells, such as fumigation incubation (Jenkinson and Pawlson, 1976) and fumigation extraction (Vance et al., 1987).

Collaterally, the release of VOCs and/or gases from soil microcosms was measured in headspace through an E-nose. The evolution of all these parameters was monitored over a 23-day period, during which nutrients were supplied twice to soil microcosm: at the inoculation time and after $21 \mathrm{~d}$ of incubation, in order to confirm the relationship between E-nose readouts and microbial activity measurements in these ecosystems. In order to test these parameters, suitable amounts of samples from soils and headspace, in accordance with the different methods to perform, were sacrificially and randomly collected from microcosms (4 replicates), except otherwise stated, at $T_{0}$ and after 1, 2, 6, 21 and 23 days (d) of incubation, except for E-nose at $T_{0}$ and SIR- $C_{\text {mic }}$ at $1 \mathrm{~d}$ measurements that were not performed (in the latter case because not applicable, according to what reported by Anderson and Domsch, 1978 and Blagodatskaya et al., 2007). It is known, in fact, that the SIR method should not be carried out in soils recently amended with available $C$ (Anderson and Domsch, 1978). Growing cells under these conditions, in fact, releases more $\mathrm{CO}_{2}$ per mass unit than is released by non-growing cells (stationary phase), so that the respiratory response to the subsequent addition of glucose to estimate microbial growth is suppressed (Blagodatskaya et al., 2007), and the relative standard factor used in Anderson and Domsch (1978) equation is not applicable. Then, $48 \mathrm{~h}$ from nutrient supply were waited before using this method, as a consequence of the results reported by Blagodatskaya et al. (2007). To test the different parameters, distinct soil microcosms were set up, according to the requirements of the specific procedures used: a set of glass flasks for both soil enzyme activities and CFU detection, another set of glass flasks for the E-nose measurements and a set of glass vessels, for both respiration detection and SIR- $C_{m i c}$ measurements.

\subsection{Soil microcosms set up}

Samples of silty clay loam soil from a grassland area nearby Rome (Italy) were collected from the top $15 \mathrm{~cm}$, after turf removal, sieved at $2 \mathrm{~mm}$ mesh and stored at $4{ }^{\circ} \mathrm{C}$ for 3 months before use, according to Lee et al. (2007). Pertinent characteristics of the soil include: sand, $182 \mathrm{~g} \mathrm{k}^{-1}$; silt, $367 \mathrm{~g} \mathrm{~kg}^{-1}$; clay, $451 \mathrm{~g} \mathrm{~kg}^{-1}$; organic $\mathrm{C}$ $\left(\mathrm{C}_{\text {org }}\right), 17.7 \mathrm{~g} \mathrm{~kg}^{-1}$; total $\mathrm{N}, 2.1 \mathrm{~g} \mathrm{~kg}^{-1} ; \mathrm{C}: \mathrm{N}$ ratio, 8.4; cation exchange capacity (CEC), $37.4 \mathrm{cmol}(+) \mathrm{kg}^{-1}$ soil; $\mathrm{pH}_{\mathrm{KCl}}, 6.03$; water holding capacity (WHC), $517.8 \mathrm{~g} \mathrm{~kg}^{-1}$. Physical, chemical and physicochemical properties were determined according to the following methods: soil texture by Lotti and Galoppini (1980), CEC, $\mathrm{C}_{\text {org }}$, total $\mathrm{N}$, WHC and $\mathrm{pH}_{\mathrm{KCl}}$ by Violante (2000). Before assembling soil microcosm, a suitable amount of soil was stored at $25^{\circ} \mathrm{C}$ in the dark for $7 \mathrm{~d}$ to allow microbial biomass to recover its activity and consume all the available low-weight organic molecules, which could have altered the forthcoming response during the experiments. This is a common practice in soil studies to avoid the effects of disturbance upon storage (Renella et al., 2007; Vance and Nadkarni, 1990) and it is also based on the findings of Brookes et al. (2008) and De Nobili et al. (2001) about the use of lowmolecular weight triggering substances by soils and in accordance with the timing of their degradation reported by Allen and Schlesinger (2004). This procedure also allowed soil enzyme activities in the original soil to be measured. A sub-sample of this soil was sterilised by $40 \mathrm{kGy} \gamma$-irradiation from a ${ }^{60} \mathrm{Co}$ source performed at $2 \mathrm{kGy} \mathrm{h}^{-1}$ for $20 \mathrm{~h}$ (Gammacell 220, Nordion, Canada). Irradiating the soil ensured that the only living organisms came from the bacterial inoculum in order to arrange suitable soil ecosystems. In order to prevent contamination of sterile soil microcosms, all the procedures after $\gamma$-irradiation were performed in sterility and all laboratory materials and reagents were sterilised prior to use or to their additions to soil.

Soil microcosms in the glass flasks were set up by weighing aliquots of sterilised soil corresponding to $15 \mathrm{~g}$ dry weight in $100 \mathrm{~mL}$ glass flasks (i.e. $140 \mathrm{~mL}$ actual volume). In control microcosms, a solution containing inorganic nutrients and glucose was added at fixed ratio to dry matter (i.e. $0.3 \mathrm{mg} \mathrm{MgSO}_{4} \cdot 7 \mathrm{H}_{2} \mathrm{O}, 1 \mathrm{mg}$

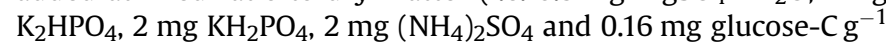
dry soil; C:N ratio, 14.3; C:P ratio, 7.8). Such a solution was used also to bring soil to $50 \%$ of its WHC. Incidentally, soil water content in the range $50-65 \%$ of WHC are commonly used in soil experiments to have the greatest microbial activities (Orchard and Cook, 1983; Linn and Doran, 1984; Davidson et al., 2000) and to make different studies comparable. In inoculated soil ecosystems, instead, about $5.5 \pm 0.3 \times 10^{4}$ total cells $g^{-1}$ dry soil of Pseudomonas fluorescens isolated from the same soil were added to soil microcosms together with the nutrient solution, after determination through direct microscopy after Acridine Orange staining (AODC) as described by Di Mattia et al. (2002). To prepare the inoculum, soil bacteria were grown overnight at $28^{\circ} \mathrm{C}$ in the nutrient solution, reported above as liquid medium, before inoculation. The inoculum density was standardised prior to the addition to soil. After the addition of nutrients with or without microbial inoculum (i.e. in control or inoculated ecosystems, respectively), soil was carefully mixed prior to seal the flasks with polypropylene stoppers to place them in a thermostatic incubator set at $30^{\circ} \mathrm{C}$ in darkness for $23 \mathrm{~d}$. The flasks used for E-nose measurements were sealed with twoways stoppers, instead. The two outlets of the stoppers were tightly closed to prevent any possible gas and VOCs leakages from the flasks during the incubation period. After $21 \mathrm{~d}$, the stoppers were removed, soil microcosms were thoroughly aerated and a further aliquot of nutrient solution, equivalent in total nutrients to the previous one but deprived of bacteria and halved in volume, was resupplied to both control and inoculated soil ecosystems. The added solution brought soil moisture to $63 \%$ of WHC, according to the study by Ravnskov and Jakobsen (1999) with P. fluorescens. Soils were then mixed carefully, stoppered again and incubated for further $48 \mathrm{~h}$. 
Soil microcosms used for soil respiration and SIR- $C_{\text {mic }}$ detection were set up, instead, by weighing soil aliquots corresponding to $2.6 \mathrm{~g}$ dry soil in $22 \mathrm{~mL}$ glass vials for both control and inoculated ecosystems, in order to maintain the same proportion between soil and headspace in soil microcosms as well as for the other measurements. Nutrients \pm microbial inoculum were added to soil, proportionally to what reported for ecosystems in flasks, at both $T_{0}$, before sealing with PTFE/silicone caps, and after cap removal and aeration at $21 \mathrm{~d}$ of incubation, as described for flasks, then mixed carefully, sealed thereafter with caps and incubated at $30^{\circ} \mathrm{C}$ in darkness for global $23 \mathrm{~d}$.

\subsection{Microbial analyses}

The quantification of microbial population through the SIR method was performed according to Bailey et al. (2008) by supplying $0.400 \mathrm{mg}$ glucose- $\mathrm{C} \mathrm{g}^{-1}$ of dry soil in solution to microcosms in order to allow the growth of microorganisms in all soil microsites and bringing soil moisture up to 57\% WHC, in accordance with what reported by Höper (2006) (but about 80\% WHC at $23 \mathrm{~d}$ ). The amount of glucose-C was 3.5 the optimal glucose- $C$ concentration suggested by Höper (2006) for arable soils with expected microbial biomass lower than $800 \mu \mathrm{g} \mathrm{C} \mathrm{g}^{-1}$ dry soil, i.e. it enabled to perform the method although it was impossible to predict the maximum microbial biomass achievable in soil ecosystems tested in the present study. Soil was then mixed and briefly flushed with hydrated air and microcosms were immediately capped and incubated at $22^{\circ} \mathrm{C}$ (checked by a digital thermometer) for $1.5 \mathrm{~h}$. The $1.5 \mathrm{~h}$ incubation was chosen since for the first $3 \mathrm{~h}$ the respiration rate is constant, according to what reported by Anderson and Domsch (1978) and Höper (2006). CFU count was carried out following the method described by Mascher et al. (2003). The catalytic activities of APase, GLUase, FDAHase, ASase and PROase were carried out according to the procedures reported by Shaw and Burns (2006), Dick et al. (1996), Green et al. (2006), Tabatabai (1994) and Ladd and Butler (1972), respectively. The amount of $\mathrm{CO}_{2}$ release to measure both SIR- $\mathrm{C}_{\text {mic }}$ and respiration in soil microcosms was determined by withdrawing $500 \mu \mathrm{l}$ aliquots from headspace through a plastic syringe and injecting them into a GC-MS coupled system. The GC (Hewlett-Packard 5890, Series 1/ II, Wilmington, DE, USA) was equipped with a capillary column PoraPLOT U (25 m, i.d., $0.320 \mathrm{~mm}$, film thickness, $10 \mu \mathrm{m}$, Chrompack, Middelburg, The Netherlands). Respiration was reported both as $\mu \mathrm{g} \mathrm{CO}_{2}-\mathrm{C} \mathrm{g}^{-1}$ dry soil of $\mathrm{CO}_{2}$ accumulated in soil microcosm headspace $\left(\mathrm{CCO}_{2}=\right.$ cumulative $\left.\mathrm{CO}_{2}\right)$ and as $\mu \mathrm{g}$ of $\mathrm{CO}_{2}-\mathrm{Ch}^{-1} \mathrm{~g}^{-1}$ dry soil produced between two next sampling dates $\left(\mathrm{CER}=\mathrm{CO}_{2}\right.$ evolution rate), reckoned from the cumulative $\mathrm{CO}_{2}$ measures. The respiration:biomass ratio (also known as metabolic quotient) was also calculated as the global $\mathrm{CO}_{2}$ produced per unit of microbial biomass $\left(\mathrm{CO}_{2} \mathrm{SIR}-\mathrm{C}_{\text {mic }}^{-1}\right.$ ratio) and unit of time $\left(\mathrm{CO}_{2}-\mathrm{CSIR}-\mathrm{C}_{\text {mic }}^{-1} \mathrm{~h}^{-1}\right)$, according to Smolander et al. (1994), measured at each sampling date. All enzyme activities were tested both in the original soil before and after $\gamma$-irradiation (Table 1 ) and during the incubation.

\subsection{Soil microbial activity as measured through gas and/or VOCs perception by an E-nose}

The E-nose used in this work was analogous to that one previously set up by the IMM-CNR of Rome (Italy) (De Cesare et al., 2008), and it was based on 8 chemical sensors consisting of QCMs coated with different organic polymers and oscillating at $20 \mathrm{MHz}$ in a $10 \mathrm{~mL}$ measuring chamber. However in the present study, the list of employed polymers included 3 different metalloporphyrins Mn5,10,15,20-tetrakis-(4-butyloxyphenylporphyrin) (QCM6), Co-5,10, 15,20-tetrakis-(4-butyloxyphenylporphyrin) (QCM7), Cu-5,10,15,20-
Table 1

Enzyme activities measured in the original soil prior and after the sterilisation procedure. APase $=$ acid phosphatase activity; GLUase $=\beta$-glucosidase activity; FDAHase $=$ FDA hydrolases activity; PROase $=$ protease activity. Enzyme activities are reported with relative standard deviation among 4 randomly sampled soil aliquots.

\begin{tabular}{llc}
\hline $\begin{array}{l}\text { Biochemical } \\
\text { activity }\end{array}$ & $\begin{array}{l}\text { Original soil }(\mu \mathrm{g} \text { of released } \\
\left.\text { product } \mathrm{h}^{-1} \mathrm{~g}^{-1} \text { of dry soil }\right)\end{array}$ & $\begin{array}{l}\text { Sterilised soil }(\mu \mathrm{g} \text { of released } \\
\left.\text { product } \mathrm{h}^{-1} \mathrm{~g}^{-1} \text { of dry soil }\right)\end{array}$ \\
\hline APase & $756 \pm 17$ & $59 \pm 3$ \\
FDAHase & $287 \pm 54$ & $0 \pm 1$ \\
GLUase & $239 \pm 6$ & $0.6 \pm 0.2$ \\
PROase & $142 \pm 7$ & $45 \pm 2.8$ \\
ASase & $97 \pm 3$ & $0 \pm 0.2$ \\
\hline
\end{tabular}

tetrakis-(4-butyloxyphenylporphyrin) (QCM8) (Di Natale et al., 2004) and 5 commercial polymers: polyethylenimmine (QCM4), polyamide (QCM2), polyaniline (QCM3), polyphenylmethylsilloxane (QCM5), perfluorocyclobutane (QCM1). All polymers except metalloporphyrins were purchased from Sigma-Aldrich, while metalloporphyrins were synthesised in laboratory (Di Natale et al., 2004). Since the possible chemical nature of VOCs and/or gases released by possible different metabolisms throughout the incubation period was unknown, we decided to choose these polymers on the base of a general chemical classification, based on different polarity and affinity to water. Incidentally, E-nose devices are commonly characterised by good selectivity but low specificity, as reported above (Pearce et al., 2003). In this case, the selected polymers were characterised by highly hydrophilic (metalloporphyrins) up to highly hydrophobic (perfluorocyclobutane) chemical nature. In previous studies on different subjects, instead, we selected polymers on the base of their chemical features as electron acceptor (as occurred for the ammonia detection reported in De Cesare et al., 2009) or on their high reactivity and coordination properties or on their chromatographic-like behaviour upon differential retention on a stationary phase characterised by hydrophilic or hydrophobic properties (as happened for the detection of phenanthrene and its metabolites reported in De Cesare et al., 2008). The polymers here chosen were deposited on both sides of quartz microbalances through evaporation under vacuum (metalloporphyrins), plasma enhanced chemical vapour deposition (perfluorocyclobutane), or spray-casting (polymers solved in suitable solvents).

The QCM mass variations upon adsorption of VOCs and/or gases present in soil microcosm headspace determined a frequency variation proportional to the mass of analytes, according to Sauerbrey's equation: $\Delta f=-k_{q} \Delta m$, where $k_{q}$ is a constant depending on quartz properties. Every data analysis was carried out using the frequency shifts between baseline and the values after reaching the analyte sorption equilibrium. VOCs and/or gases were withdrawn from soil headspace and drawn into the E-nose chamber by a micropump $\left(200 \mathrm{~mL} \mathrm{~min}^{-1}\right)$, while the temperature $\left(30^{\circ} \mathrm{C}\right)$ was controlled by a thermostatic chamber. Measurements were carried out twice for each group of 4 replicates per treatment (control and inoculated ecosystems), per sampling date. The reproducibility of the measurements was tested through ANOVA using the replicated measures obtained from the same samples at each sampling date as two distinct groups of data. This data processing was repeated for each sensor and the ANOVA did not show any significant difference at $P<0.05$ between the replicates.

\subsection{Statistics}

One measurement per microcosm was carried out to quantify CFU, and enzyme activities, except for VOCs and/or gases release estimation through the E-nose and respiration and FDAHase 
activity detection, which were measured twice in each microcosm. In these cases the two values were averaged before further data processing to equalise the number of measures to compare per each parameter. Since data at $1 \mathrm{~d}$ sampling relative to $S I R-C_{\text {mic }}$ were lacking, the total vital microbial biomass values relative to this sampling were calculated from the CFU measures using the conversion factor reported by Taylor et al. (2002), in order to allow statistical analyses.

Measurements of enzyme activities, microbial parameters and $\mathrm{CO}_{2}$ evolution were analysed by ANOVA to test their dependence on incubation time and soil treatments as independent variables and the significance of their relative differences. Correlations among biochemical and microbiological parameters were also tested through the calculation of the Pearson's correlation using StatPlus:mac LE.2009 by AnalystSoft, Inc., Canada.

Furthermore, microbiological and biochemical measures were analysed through multivariate analyses. Multivariate analyses are often used in soil sciences to test the effects of various treatments, managements or soil parameters on other soil parameters. The application of such analyses to microbiological and biochemical parameters has been recently used to provide also a more holistic representation of the biochemical and microbial features of soils (Nannipieri et al., 2002; Hinojosa et al., 2004). Specifically in this study, PCA and PLS (using PLS Toolbox software by Eigenvector Research, Inc., USA) applied to all kinds of measures relative to samplings from 1 to $23 \mathrm{~d}$, as data set, were carried out. These analyses combined altogether the measures of all different parameters relative to each sample into a single value (microbial index) through mathematical algorithms, though saving the information regarding each parameter (Nannipieri et al., 2002). The resulting information can also be used to assess the contribution of each parameter on the multivariate classification (through biplot of loadings). Specifically, while PCA graphically represents the correlation of these indices in an n-dimensional space through their spatial distribution on the base of similarities and diversities, PLS (both PLS-DA, i.e. PLS-discriminant analysis, and PLS-regression) allows the construction of a model on the basis of a group of indices from an n-dimensional matrix (X-block), as for PCA, and then uses each index of an m-dimensional matrix (Y-block) to validate the model according to the leave-one-out principle. Biplot of loadings is a type of graph used in statistics, which permits information on both samples and variables of a data matrix to be displayed graphically. Also sensors array responses during E-nose measurements, deriving from adsorption onto polymeric films of analytes released from soil ecosystems into headspace, were analysed by PCA and PLS data processing and biplot was also carried out. All analyses on sensory data were carried out using the frequency shifts of each sensor as data set.

Each data set used for different multivariate analyses was previously autoscaled $(\mu=0, \sigma=1)$.

\section{Results}

\subsection{Microbiological and biochemical measurements}

\subsubsection{Microbial biomass}

Microbial biomass in inoculated soil ecosystems showed similar but not identical trends, represented by an initial steep increase, a following decrease and then a further increment, when measured either as SIR- $\mathrm{C}_{\text {mic }}$ or as CFU in aliquots of soil sampled from soil microcosms at different dates over $23 \mathrm{~d}$ of incubation (Fig. 1). Both trends were significantly dependent (CFU at $P<0.001$ and SIR- $C_{\text {mic }}$ at $P<0.05)$ on the incubation period. However, CFU estimation indicated that the exponential phase of bacterial growth occurred between $T_{0}$ and 1-2 $\mathrm{d}$ of incubation following inoculum addition to

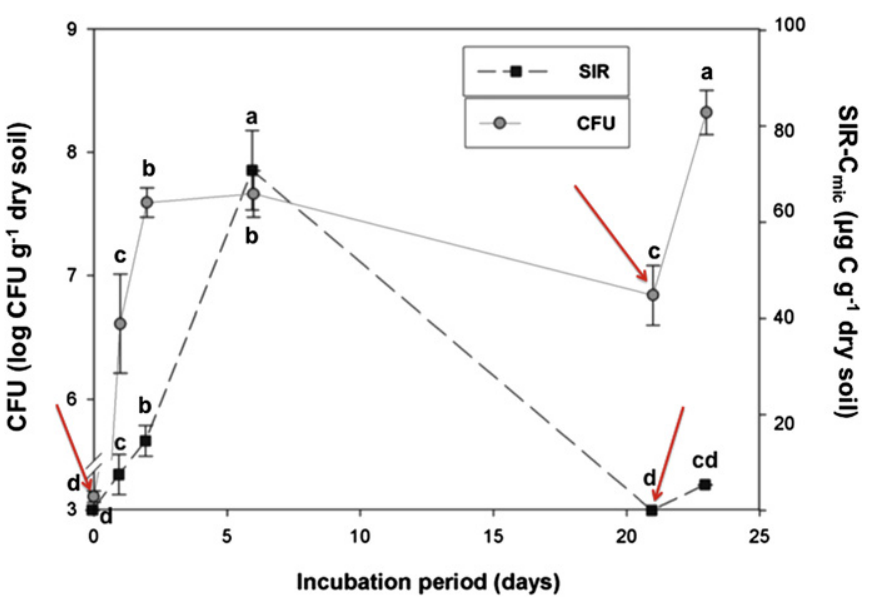

Fig. 1. Microbial biomass content measured as culturable and viable cells (CFU) and as total vital biomass (SIR- $C_{\text {mic }}$ ) in inoculated ecosystems over $23 \mathrm{~d}$ incubation. The biomass content measured by SIR at $1 \mathrm{~d}$ was reckoned on the base of the relationships between CFU and total microbial biomass reported by Taylor et al. (2002). Arrows represent nutritive pulse supplied to soil. Bars represent standard deviation $(n=4)$. Letters represent significant differences $(P<0.001)$ between the means.

the soil, despite with two distinct slopes, then followed by a stationary phase up to $6 \mathrm{~d}$, while SIR-C mic showed that the exponential phase of growth continued for up to $6 \mathrm{~d}$ of incubation. Thereafter, microbial growth decreased till $21 \mathrm{~d}$ up to approximately zero (SIR- $C_{\text {mic }}$ ) or to values comparable to those at $1 \mathrm{~d}$ (CFU) (resting or death phase). After further nutrient supply to the soil, the SIR- $C_{\text {mic }}$ increased, but the increment was not significant, while a second exponential phase was observed in culturable cells. Both SIR- $\mathrm{C}_{\text {mic }}$ and CFU appeared absent in the non-inoculated controls (data not shown).

\subsubsection{Carbon dioxide content}

Measurements of $\mathrm{CO}_{2}$ production in sterilised and inoculated soil ecosystems, measured as $\mathrm{CCO}_{2}$, showed significant variations $(P<0.001)$ over time (Fig. 2). Cumulative $\mathrm{CO}_{2}$ levels in the microcosm headspace increased up to $897 \mu \mathrm{g} \mathrm{CO}_{2}-\mathrm{Cg}^{-1}$ dry soil within $2 \mathrm{~d}$; this increase was a consequence of the increments of CER (up to $18.55 \mu \mathrm{g} \mathrm{CO}_{2}-\mathrm{Ch}^{-1} \mathrm{~g}^{-1}$ dry soil) at the expense of $\mathrm{O}_{2}$, which was used as principal electron acceptor, according to the characteristics of the microbial species, and of the $\mathrm{CO}_{2}$ SIR- $\mathrm{C}_{\text {mic }}^{-1}$ ratio, which reached the highest value $\left(3.5 \mathrm{CO}_{2}-\mathrm{CSIR}-\mathrm{C}_{\text {mic }}^{-1} \mathrm{~h}^{-1}\right)$ after the first $24 \mathrm{~h}$ of incubation (Fig. 2 inset). All these 3 parameters showed very high increments but 2 different slopes during the first $48 \mathrm{~h}$ of incubation, where the steepest one occurred within the first $24 \mathrm{~h}$, probably because $\mathrm{CO}_{2}$ SIR- $\mathrm{C}_{\text {mic }}^{-1}$ ratio decreased during the next $24 \mathrm{~h}$ $\left(1.29 \mathrm{CO}_{2}-\mathrm{C} \mathrm{SIR}-\mathrm{C}_{\text {mic }}^{-1} \mathrm{~h}^{-1}\right)$. Thereafter, $\mathrm{CCO}_{2}$ continued to increase, despite more gradually, up to $1346 \mu \mathrm{g} \mathrm{CO}_{2}-\mathrm{Cg}^{-1}$ dry soil ( $6 \mathrm{~d}$ of incubation), as a consequence of the precipitous reduction of CER to about $4.69 \mu \mathrm{g} \mathrm{CO}_{2}-\mathrm{Ch}^{-1} \mathrm{~g}^{-1}$ dry soil and of the $\mathrm{CO}_{2}$ SIR-C $\mathrm{C}_{\text {mic }}^{-1}$ ratio $\left(0.4 \mathrm{CO}_{2}-\mathrm{C} \mathrm{SIR}-\mathrm{C}_{\text {mic }}^{-1} \mathrm{~h}^{-1}\right)$, between $2 \mathrm{~d}$ and $6 \mathrm{~d}$ of incubation. These results are in agreement with those reported by Blagodatskaya et al. (2007) and Vance and Nadkarni (1990). Then, $\mathrm{CCO}_{2}$ in soil microcosm headspace decreased to minimal values $\left(273 \mu \mathrm{g} \mathrm{CO} \mathrm{CO}_{2}-\mathrm{g} \mathrm{g}^{-1}\right.$ dry soil) upon the drastic reduction of CER up to even negative values $\left(-2.98 \mu \mathrm{g} \mathrm{CO}_{2}-\mathrm{Ch}^{-1} \mathrm{~g}^{-1}\right.$ dry soil) at $21 \mathrm{~d}$, suggesting the possibility for the occurrence of heterotrophic fixation. The term "heterotrophic $\mathrm{CO}_{2}$ fixation" or "heterotrophic $\mathrm{CO}_{2}$ assimilation" (Wood and Werkman, 1936) refers to $\mathrm{CO}_{2}$ incorporation into organic metabolites by chemo-organo-heterotrophic microorganisms including bacteria (e.g. P. fluorescens) (Miltner et al., 2004; Hesselsoe et al., 2005), through the action of various carboxylases involved in various metabolic pathways such as the anaplerotic reactions that 


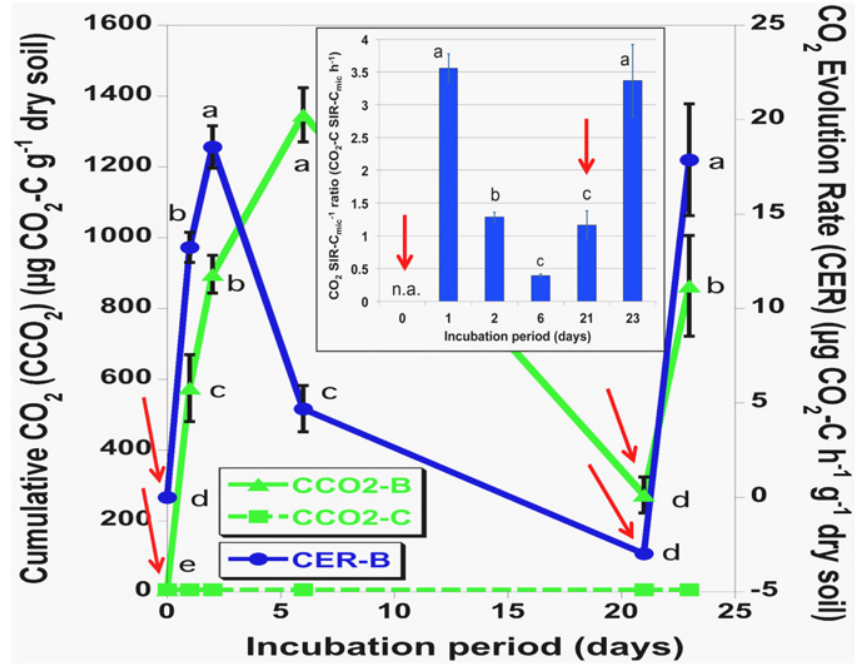

Fig. 2. Microbial respiration measured as $\mu \mathrm{g} \mathrm{CO} 2-\mathrm{Cg}^{-1}$ dry soil accumulated in headspace of both inoculated and non-inoculated soil microcosms (cumulative $\mathrm{CO}_{2}-\mathrm{CCO}_{2}$ ), and as $\mu \mathrm{g} \mathrm{CO}_{2}-\mathrm{Ch}^{-1} \mathrm{~g}^{-1}$ dry soil released in microcosm headspace between two consecutive sampling dates $\left(\mathrm{CO}_{2}\right.$ evolution rate - $\left.\mathrm{CER}\right)$ over $23 \mathrm{~d}$ incubation. Inset shows the $\mathrm{CO}_{2}$ SIR- $\mathrm{C}_{\text {mic }}^{-1}$ ratio reckoned over the same period. Arrows represent nutritive pulse supplied to soil. Bars represent standard deviation $(n=4)$. Letters represent significant differences $(P<0.001)$ between the means within each treatment.

refurnish the tricarboxylic acid cycle (TCC) (Kornbeg, 1966) and others (Dijkhuizen and Harder, 1985). Respiration and heterotrophic fixation commonly coexist in soil, and soil $\mathrm{CO}_{2}$ concentration results from the prevalence of one metabolic process over the other. The extent of this fixation usually ranges from 1 to $13 \%$ of the organic $\mathrm{C}_{\text {mic }}$ (Perez and Matin, 1982; Santruckova et al., 2005). Notwithstanding, it may only slightly justify the drastic decrease in $\mathrm{CO}_{2}-\mathrm{C}$ observed in the present study. However, the few studies carried out to assess the presence and the extent of heterotrophic $\mathrm{CO}_{2}$ fixation in soil never used environmental conditions (i.e. $\mathrm{CO}_{2}$ concentrations) similar to the microaerophilic or even anaerobic conditions presumably occurring in soil ecosystems set up in the present study. In the study of Santruckova et al. (2005) and Miltner et al. (2004), for example, $5 \%$ and $1 \% \mathrm{CO}_{2}$ concentrations were used as high $\mathrm{CO}_{2}$ conditions, respectively, i.e. very far from the common $\mathrm{CO}_{2}$ concentrations in soils and from those occurring in the present study. Therefore, the possible extent of heterotrophic $\mathrm{CO}_{2}$ fixation in anaerobic conditions in soil is still unknown, although evidences for heterotrophic $\mathrm{CO}_{2}$ fixation in such environments have been reported (Hesselsoe et al., 2005). Other possible mechanisms to explain the $\mathrm{CO}_{2}$ decrease in terms of $\mathrm{CO}_{2}$ fixation have been listed by Miltner et al. (2004), but are not applicable for the bacterial species used in the present study. Further possible explanations for such a diminution can be ascribed to abiotic processes such as carbonate precipitations, as a consequence of increased $\mathrm{CO}_{2}$ solubilisation at high $\mathrm{CO}_{2}$ partial pressure in the slightly acidic clay loam soil used in this study ( $\mathrm{pH} 6.3$ ), especially in the case of adequate concentrations of $\mathrm{Ca}^{2+}$ and $\mathrm{Mg}^{2+}$ ions (not tested). Furthermore, physical adsorption of $\mathrm{CO}_{2}$ onto soil particles (especially in soil with great specific surface area, as assumable for the clay loam soil here used) may also occur. In any case, the truthfulness of the $\mathrm{CO}_{2}$ decrease here observed in soil ecosystems in sealed vessels was confirmed by the completely randomised sampling procedure, which included the microcosms at $21 \mathrm{~d}$, by the 4 replicates used and by the contemporary decrease in all parameters tested (i.e. through both common biochemical and microbiological methodologies and E-nose, which involved the use also of different containers), so that any possible gas leaching can be excluded. Additionally, in completely independent studies carried out in our laboratory involving a forest soil in natural conditions (not sterilised) and focused on pollutant degradation, a similar drastic decrement in $\mathrm{CO}_{2}$ content of headspace was observed, after a certain incubation period (unpublished results). Hence, although a completely satisfactorily explanation for such a $\mathrm{CO}_{2}$ decrease cannot be identified, we are sure about the truthfulness of our results and then further studies are necessary to clarify this event. However, shortly after the second pulse of nutrients to the soil, CER rose again steeply to $17.87 \mu \mathrm{g} \mathrm{CO}_{2}-\mathrm{Ch}^{-1} \mathrm{~g}^{-1}$ dry soil (i.e. not significantly different from what measured after $2 \mathrm{~d}$ ), with a trend resembling that observed within the same lapse of time after the first supply of nutrients and similarly to what happened to the $\mathrm{CO}_{2}$ SIR- $\mathrm{C}_{\text {mic }}^{-1}$ ratio $\left(3.37 \mathrm{CO}_{2}-\mathrm{C} \mathrm{SIR}-\mathrm{C}_{\text {mic }}^{-1} \mathrm{~h}^{-1}\right) . \mathrm{CO}_{2}$ also accumulated in soil headspace, as it had occurred after the first $2 \mathrm{~d}$ of incubation (894 $\mu \mathrm{g} \mathrm{CO}_{2}-\mathrm{C} \mathrm{g}^{-1}$ dry soil). No significant variation from the $\mathrm{CO}_{2}$ concentration measured at $T_{0}$ (ambient $\mathrm{CO}_{2}$ ) was observed in soil without bacterial inoculum throughout the incubation period.

\subsubsection{Enzyme activities in soil}

The measurements of enzyme activities in the original soil showed that all of the catalytic activities tested were present. All enzyme activities tested were greatly reduced or suppressed by the $\gamma$-irradiation procedure used to sterilise the soil (Table 1 ). Only $8 \%$ and $29 \%$ of the original catalytic activities of APase and PROase, respectively, were still present after sterilisation (immobilised enzymes (Burns, 1982)), while all other enzyme activities were suppressed. All enzyme activities in soil ecosystems were significantly affected $(P<0.001)$ by the presence of microorganisms and by the incubation period. All the hydrolytic activities changed after nutrient supply with slopes reflecting the general trends proposed by Renella et al. (2007) for soil enzymes after amendments with organic compounds and nutrients. Shortly after inoculation of soil microcosms with P. fluorescens, APase activity was even greater than that in the original soil (Fig. 3a). This catalytic activity achieved its maximal activity $(+33 \%, P<0.001)$ between $T_{0}$ and $1 \mathrm{~d}$ of incubation; from 1 to $6 \mathrm{~d}$ of incubation, it was strongly inhibited, returning to values much lower than $T_{0}$. Thereafter, APase activity was further inhibited up to $-80 \%$ at $21 \mathrm{~d}(P<0.001)$, with respect to maximum. Following the second pulse of nutrients, no significant variation was observed in this catalytic activity. After inoculation of soil with $P$. fluorescens, GLUase activity showed a sigmoid shape with rather low values that were nevertheless significantly $(P<0.001)$ greater than those of sterilised soil. GLUase activity remained constant until $1 \mathrm{~d}$ of incubation and then began increasing to reach a maximum at $2 \mathrm{~d}$ ( 7 -fold increase; $P<0.001$ ) (Fig. $3 \mathrm{~b}$ ). A gradual but drastic decrease followed this peak until $21 \mathrm{~d}(-81 \%)$; the activity increased again, but not significantly, after the second nutrient supply. FDAHase activity showed significantly $(P<0.001)$ different values in inoculated soil at $T_{0}$ with respect to the sterilised one, but they were rather lower than the maximum (Fig. 3c). The catalytic activity of FDAHase increased to a maximal value after 2-6d (3.9-fold increase, $P<0.05)$. It then showed a significant decrease $(P<0.05)$, similar to that observed in other enzymes, down to $21 \mathrm{~d}$ $(-58 \%)$. Following the second pulse of nutrients, FDAHase was the only enzyme that steeply increased its activity; at $23 \mathrm{~d}$, in fact, up to 4.6 times $(P<0.05)$ the level present at $21 \mathrm{~d}$ was observed. Plots of PROase activity showed a sigmoid shape (Fig. 3d) similar to that observed for GLUase activity. At $T_{0}$ after bacteria inoculation, PROase showed low catalytic levels, while from 1 to $6 \mathrm{~d}$ of incubation, its activity greatly increased, reaching a maximum at $6 \mathrm{~d}$ (63 times the value at $\left.T_{0} ; P<0.01\right)$. A renewed inhibition of PROase activity was observed when a second pulse of nutrients was added to soil. Of the enzymes tested, only ASase seemed unaffected at $T_{0}$ after inoculation, showing no catalytic activity and remained undetectable 

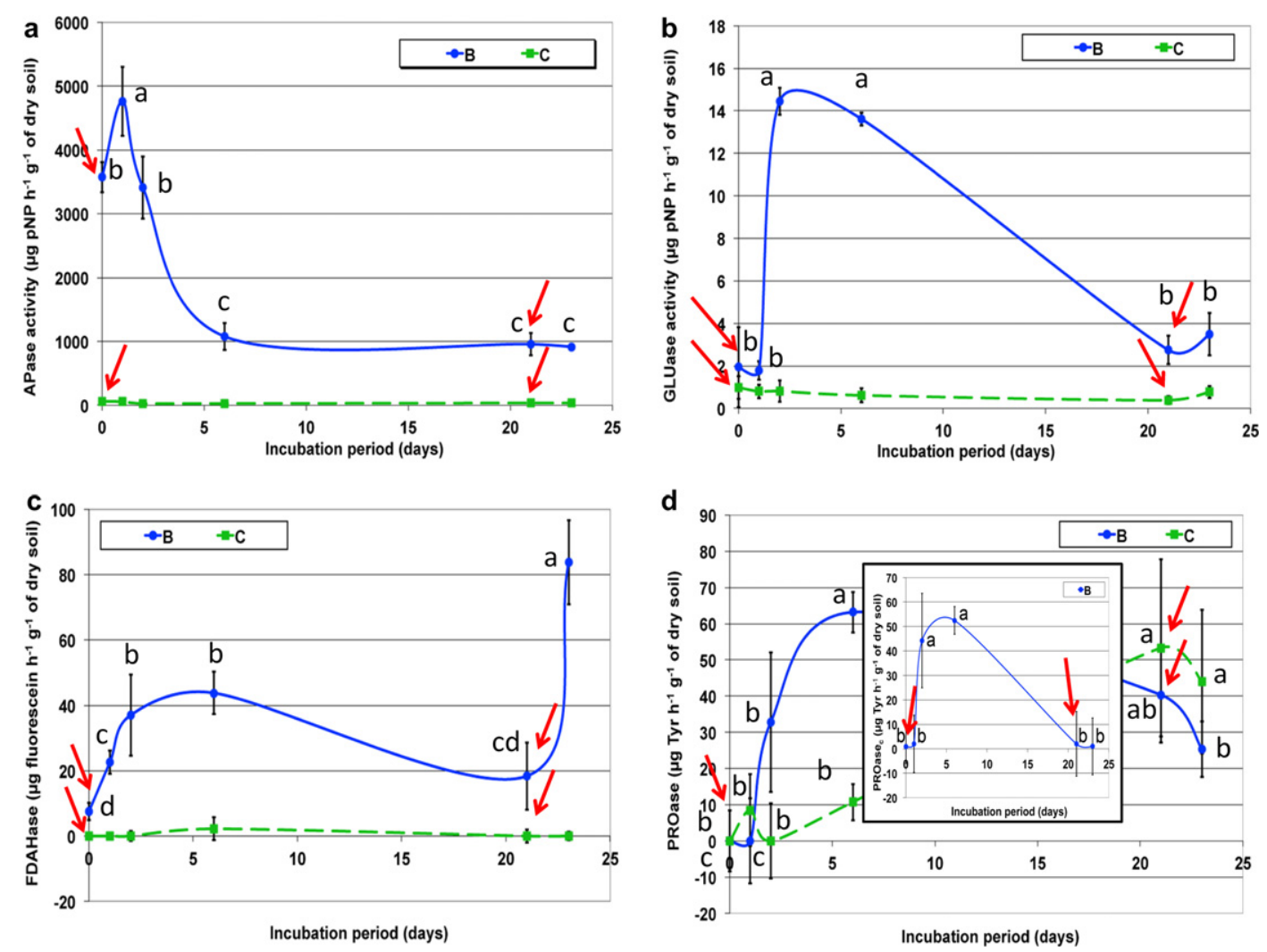

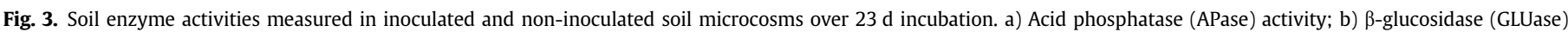

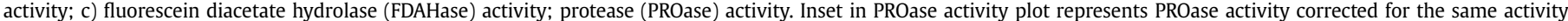

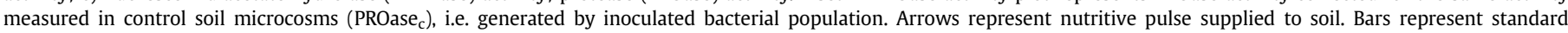

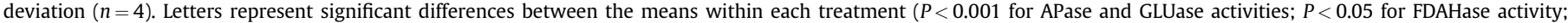
$P<0.01$ for PROase activity and $P<0.001$ for PROase activity of non-inoculated controls).

throughout the incubation period (data not shown) and then it will be not mentioned any longer in the text. In sterilised non-inoculated microcosms, none of the enzyme activities tested, except for that of PROase, varied relative to their values at $T_{0}$. In such soils, PROase activity was greatly inhibited at first $\left(T_{0}\right)$ with respect to values after sterilisation (Table 1 ) and then increased linearly with time from $2 \mathrm{~d}$ to 53 -fold the initial value $(P<0.001)$ at $21 \mathrm{~d}$ of incubation, i.e. completely recovering its original value soon after $\gamma$-irradiation. To evaluate the contribution of microbial cells to soil PROase measured, such an activity in inoculated ecosystems was corrected for the contribution of this activity in control soils, i.e. unrelated to the presence of microorganisms (PROase ${ }_{c}$ ). As shown in the inset to Fig. 3d, application of this correction showed a more consistent trend with that of other enzymes, and the rapid decrease in PROase activity following its maximum at $21 \mathrm{~d}$ varied from -36 to $-96 \%$.

\subsubsection{Multivariate analyses of microbiological}

\section{and biochemical parameters}

The results of PCA applied on all biochemical and microbiological measures (i.e. 384 measures), hereafter grouped under the term "microbial" with respect to those obtained by the E-nose classified as "sensory", are reported in a microbial fingerprint that describes the chronological evolution of soil microcosms inoculated with $P$. fluorescens (Fig. 4a). In Fig. 4a, each symbol in the three-dimensional space of variance of the PCA corresponds to the microbial index of the ecosystem. It is noteworthy that control microcosms, except those sampled after $21 \mathrm{~d}$, are greatly separated from inoculated ones and that different temporal samplings are clearly discernible within inoculated ecosystems. PC1 accounted for the greatest variance (56.77\%); it discriminated between inoculated and all control microcosms and demonstrated that metabolic conditions of inoculated soil ecosystems after $21 \mathrm{~d}$ were so poor as to be similar (not identical) to those of controls. In contrast, PC2 (24.60\%) and PC3 (12.56\%) were responsible for the chronological differentiation of measures. To assess the influence of different metabolic parameters on the microbial fingerprint, the biplot of loadings relative to all microbial parameters was carried out. This analysis showed that the discrimination between control and inoculated samples at $21 \mathrm{~d}$ was mostly due to the negative correlation with $\mathrm{CCO}_{2}$ (data not shown). Since these two groups of samples were unaffected by all parameters concerning microbial activity, they were removed from Fig. 4b, which reports the biplot as depicted on PC2 and PC3, where all clusters relative to the other sampling dates showed their maximum spread and separation. The discrimination of these clusters was ascribable to different parameters, as follows. The samples at $1 \mathrm{~d}$ and $23 \mathrm{~d}$ were discriminated from those at $2 \mathrm{~d}$ and $6 \mathrm{~d}$ upon APase and FDHase activities, CER, CFU and $\mathrm{CO}_{2}$ SIR- $\mathrm{C}_{\text {mic }}^{-1}$ ratio, which mostly affected the first two clusters, while GLUase and PROase ${ }_{c}$ activities, SIR- $C_{\text {mic }}$ and partially $\mathrm{CCO}_{2}$ influenced the other groups of samples. APase activity was the main discriminant for $1 \mathrm{~d}$ sampling, when combined to the effect of CER and $\mathrm{CO}_{2}$ SIR- $\mathrm{C}_{\text {mic }}^{-1}$ ratio, while FDAHase activity and CFU were the parameters mainly affecting the samples at $23 \mathrm{~d}$. The distinction between $2 \mathrm{~d}$ and $6 \mathrm{~d}$ samples were due, instead, to the additional effect of APase activity to that of GLUase and PROase activities on samples at $2 \mathrm{~d}$, while microcosms collected at $6 \mathrm{~d}$ were more affected by SIR- $C_{\text {mic. }}$. Finally, the samples at $2 \mathrm{~d}$ were anticorrelated with FDAHase and CFU, while those at $6 \mathrm{~d}$ were 
a

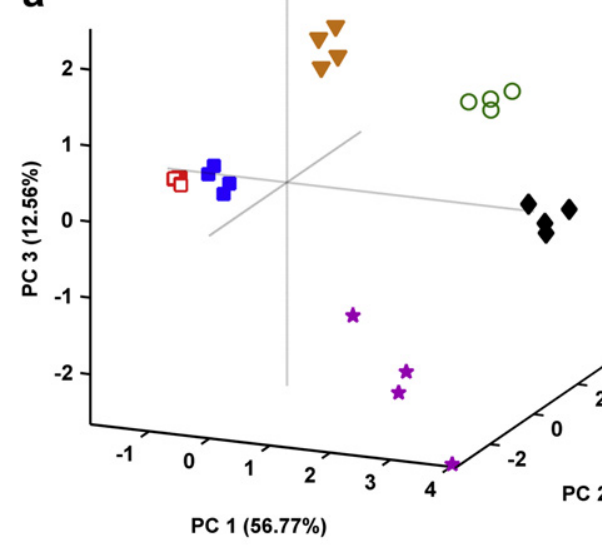

b

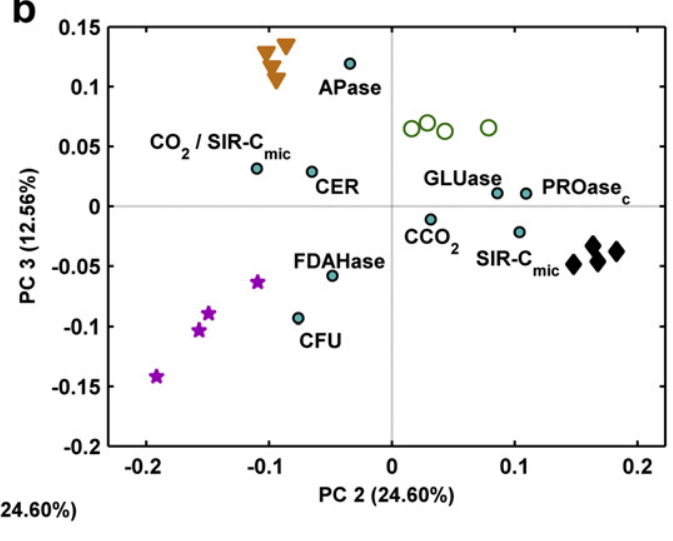

$\begin{array}{lllllllllllllll}\circ & \text { Loadings } & * & \mathrm{~B} 23 & \bullet & \mathrm{B} 21 & \bullet & \mathrm{B} 6 & \mathrm{O} & \mathrm{B} 2 & \nabla & \mathrm{B} 1 & \square & \mathrm{C}\end{array}$

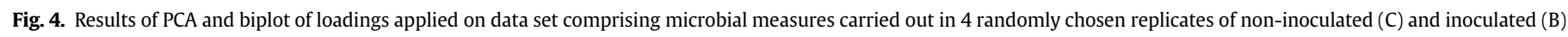

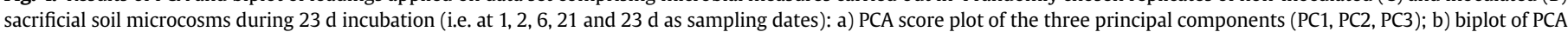

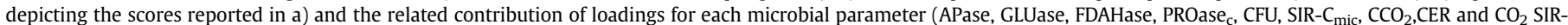

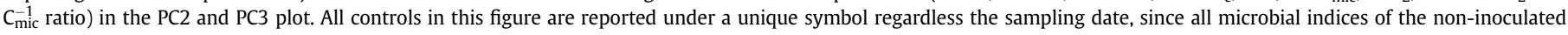
microcosms grouped together in the space of variance here reported.

anticorrelated with $\mathrm{CER}$ and $\mathrm{CO}_{2} \mathrm{SIR}-\mathrm{C}_{\text {mic }}^{-1}$ ratio. Hence, because the microbial fingerprint derived from PCA reflects both the soil metabolic activity and the growth of the metabolically active bacterial population, it might reasonably describe the metabolic fingerprint of the soil ecosystem evolving over time.

\subsection{Sensory (E-nose) responses and analyses}

The E-nose responses towards VOCs and/or gases released in headspace of inoculated and non-inoculated soil microcosms over $23 \mathrm{~d}$ of incubation (globally, 320 readouts) were transformed by PCA into a sensory fingerprint, which was more properly an olfactory fingerprint. In this odorant image, the indices created by PCA corresponding to the atmosphere of ecosystems (sensory indices) gathered in distinct clusters associated with different sampling dates during the incubation period and demonstrated the temporal evolution of headspace of soil ecosystems supplied with nutrients \pm bacteria (Fig. 5a and b). In this distribution of variance, PC1 accounted for the greatest variance (74.18\%) and succeeded in discriminating $1 \mathrm{~d}$ sampling from the other sampling dates; PC2 accounted for $19.29 \%$ of variance and succeeded in distinguishing $21 \mathrm{~d}$ sampling from that carried out at $1 \mathrm{~d}$ and $6 \mathrm{~d}$. PC3 accounted for $3.18 \%$ of variance and separated $2 \mathrm{~d}$ sampling from that performed at $21 \mathrm{~d}$ and $23 \mathrm{~d}$. Nevertheless, the microcosms sampled at $2 \mathrm{~d}$ and $6 \mathrm{~d}$ could not be resolved by PCA only. To deal with this problem, a supervised PLS-DA analysis was carried out using the E-nose data set as the X-block and the matrix indicating the relationship of each measure to a specific sampling date as the Y-block. The result of this mathematical processing, which was cross-validated by the leave-one-out processing, showed that the model correctly attributed sensory measures to distinct chronological clusters with a $10 \%$ relative error (data not shown), i.e. within the usual experimental error due to sample handling and instrumental variability. Hence, it might be reasonably presumed that different amounts and/or types of VOCs and/or gases were produced and released in soil microcosms at different periods of incubation. It was demonstrated that the E-nose might discriminate soil ecosystems at different sampling dates on the base of the adsorption of those analytes onto sensors coated with diverse polymers. However, differences in the PCA plots by varying the incubation times were observed in both control and inoculated microcosms that might appear too close in the PCA space to be actually different. The E-nose might therefore be hypothesised to be unable to distinguish inoculated from non-inoculated microcosms within each sampling date. To deal with this problem, supervised PLS-DA analysis was carried out using the sensory measures as the data set, where the X-block consisted of E-nose responses and the Y-block comprised a matrix indicating whether each measure referred to inoculated or control microcosms. This mathematical processing resulted in $90 \%$ probability for the model to correctly identify sensory measures as belonging to noninoculated soil microcosms and $94.4 \%$ probability that it correctly associated the measures with inoculated ecosystems. Since these probabilities are within the usual experimental error, it may be concluded that PCA actually discriminated also inoculated from control microcosms. To assess the influence of different sensors on perception of the released VOCs and/or gases in soil ecosystems and on their resulting olfactory fingerprint, a biplot was carried out on the previous PCA. The results of this analysis showed that, for both control and inoculated microcosms, the distinction of the clusters at $1 \mathrm{~d}$ was ascribable to the contributions of sensors QCM1, QCM3, QCM5, QCM6 and QCM7 (Fig. 5c). At $6 \mathrm{~d}$, all sensors concurrently influenced the cluster relative to this sampling, despite to different extents. In contrast, the cluster relative to the samplings carried out at $21 \mathrm{~d}$ was more affected by the contributions of sensors QCM2 and QCM3. Finally, QCM2, QCM4 and QCM8 all affected the $2 \mathrm{~d}$ and $23 \mathrm{~d}$ samplings in the PCA plot. The contributions of these latter sensors also affected the separation between inoculated and control microcosms within each cluster, as shown in Fig. $5 \mathrm{a}$ and b.

\subsection{Sensing soil ecosystems - correlations between microbial and E-nose measures}

To demonstrate definitely that E-nose responses were related to microbial activity, correlations between the measures deriving from the two different approaches were sought. The possibility to apply multivariate analyses to both groups of measures facilitated this statistical process. Accordingly, sensory data obtained over the $23 \mathrm{~d}$ incubation period were compared with microbial data through 

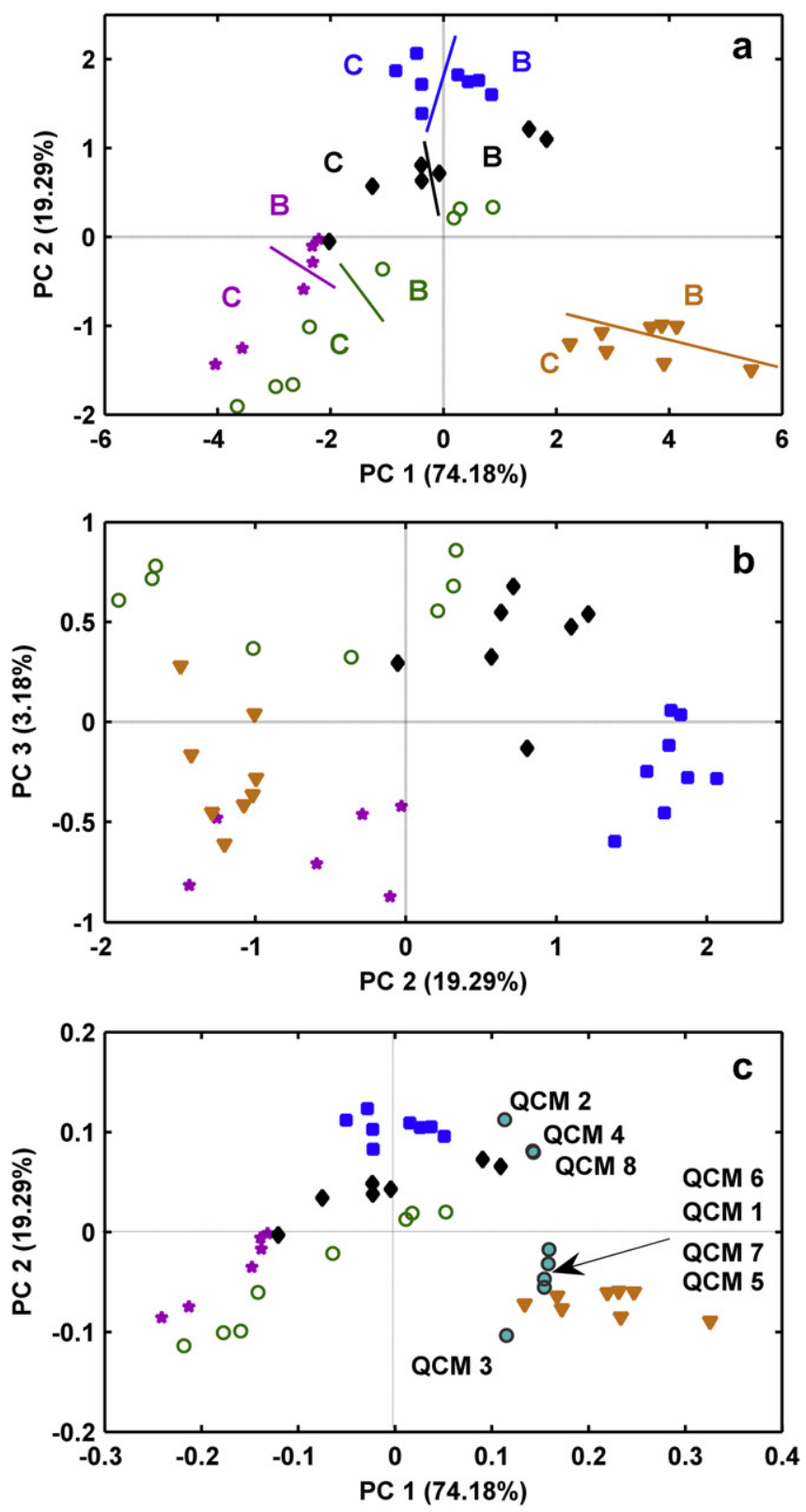

$\circ$ Loadings $* 23 \quad$\begin{tabular}{llllllll|}
\hline & $\bullet$ & $\bullet$ & 6 & $\circ$ & 2 & $\nabla$ & 1
\end{tabular}

Fig. 5. Results of PCA applied on data set consisting of headspace measures obtained through E-nose in 4 randomly chosen replicates of non-inoculated $(C)$ and inoculated (B) sacrificial soil microcosms during $23 \mathrm{~d}$ incubation (i.e. at 1, 2, 6, 21 and $23 \mathrm{~d}$ as sampling dates): a) PCA score plot of the first and second principal components (PC1, PC2); b) PCA score plot of the second and third principal components (PC2, PC3); c) biplot of PCA (with respect to the first two principal components PC1, PC2) depicts the scores reported in a) and the related contribution of loadings for each sensor included in the E-nose. Sensors are identified as follows: perfluorocyclobutane (QCM1), polyamide (QCM2), polyaniline (QCM3), polyethylenimmine (QCM4), polyphenylmethylsilloxane (QCM5), Mn-5,10,15,20-tetrakis-(4-butyloxyphenylporphyrin) (QCM6), Co-5,10,15,20-tetrakis-(4-butyloxyphenylporphyrin) (QCM7), Cu-5,10,15,20tetrakis-(4-butyloxyphenylporphyrin) (QCM8).

supervised PLS-regression analysis (globally, 320 readouts). To prevent that such a statistical analysis was affected by the background contribution of control samples observed in both E-nose and microbial measures, which might also induce misunderstandings and misinterpretations of results, and to enable the identification of the similarities and dissimilarities between trends in parameters of biotic origin only, all measures from inoculated ecosystems sampled at different incubation periods were corrected for contributions from the relative non-inoculated microcosms prior to the PLS-regression processing of data. Incidentally, such a statistical tool was used to best fit the 8-dimensional E-nose data space with each 1-dimensional microbial datum. This analysis resulted in strong regression values between the two different detecting systems (Fig. 6). As a matter of fact, the predicted values based on E-nose measures were very strongly related to measures of biochemical parameters such as APase $\left(R^{2}=0.864\right)$ (Fig. 6a), GLUase $\left(R^{2}=0.808\right)$ (Fig. 6b), FDAHase $\left(R^{2}=0.802\right)$ (Fig. 6c) and PROase $_{\mathrm{c}}\left(R^{2}=0.948\right)$ (Fig. 6d) activities, among soil enzymes, and with respiration measures such as $\mathrm{CCO}_{2}\left(R^{2}=0.843\right)$ and CER $\left(R^{2}=0.849\right)$ (Fig. 6e and $\mathrm{f}$, respectively). Interestingly, E-nose responses were highly related not only to biochemical parameters (i.e. microbial activity) but also to microbial biomass, both as SIR- $\mathrm{C}_{\text {mic }}^{-1}\left(R^{2}=0.919\right)$ and as CFU $\left(R^{2}=0.831\right)$ (Fig. 6g and $\mathrm{h}$, respectively).

\section{Discussion}

4.1. Detecting microbial activity in soil ecosystems: sensing vs. traditional approaches

The close correlation between microorganisms and VOCs production has been widely reported, and several purposes have been identified to explain such release, as mentioned in the introduction. Then, the aim of this study is to use the E-nose to measure the microbial activity in soil, on the basis of the hypothesis that different metabolic activities, expressed by enzyme activities and respiration, are able to generate different olfactory fingerprint. To achieve this purpose, it was necessary to assess, at first, not only whether the selected biochemical parameters were related to the microbiological parameters used, but also whether they were able to describe the different metabolic, physiological and growth phases of bacterial population in the soil ecosystems under study. The application of multivariate analyses to the various microbial parameters demonstrated two main findings. Firstly, that it was possible to distinguish the evolution of inoculated from those of non-inoculated microcosms over time, where $\mathrm{CO}_{2}$ was the pivotal parameter (on a multivariate basis) in discriminating between metabolically active (inoculated) and inactive (non-inoculated and those at $21 \mathrm{~d}$ ) microcosms, while several enzymes and microbiological parameters proved successful for the temporal distinction of ecosystems. Secondly, that the contemporary effect of both biochemical and microbiological parameters as component loadings in the chronological distribution of samples in the PCA, supported the idea of a close relationship between these different parameters, suggesting that enzymes were synthesised by microorganisms and followed the growth and physiological phases of the bacterial populations in the soil. During the incubation period, in fact, the inoculated bacteria experienced an early exponential growth phase within the first $24 \mathrm{~h}$, characterised by a very steep growth during which the main biochemical discriminants was APase activity, but where also CER and $\mathrm{CO}_{2}$ SIR- $\mathrm{C}_{\text {mic }}^{-1}$ were effective, while SIR- $C_{\text {mic }}$ showed some negative correlation. This first stage was followed by a late exponential phase in the next $24 \mathrm{~h}$ marked by a reduced slope in the bacterial growth, where the hydrolytic activities of GLUase and PROase ${ }_{c}$ became the predominant factors of discrimination and CFU and FDAHase activity were negatively correlated factors, relative to the previous phase. The synthesis of the former enzymes suggests the possible occurrence of nutrient limitation, such as described by other studies in similar conditions where priming effect was demonstrated to occur. In the following $4 \mathrm{~d}$, in fact, the microbial population evolved into a stationary phase 

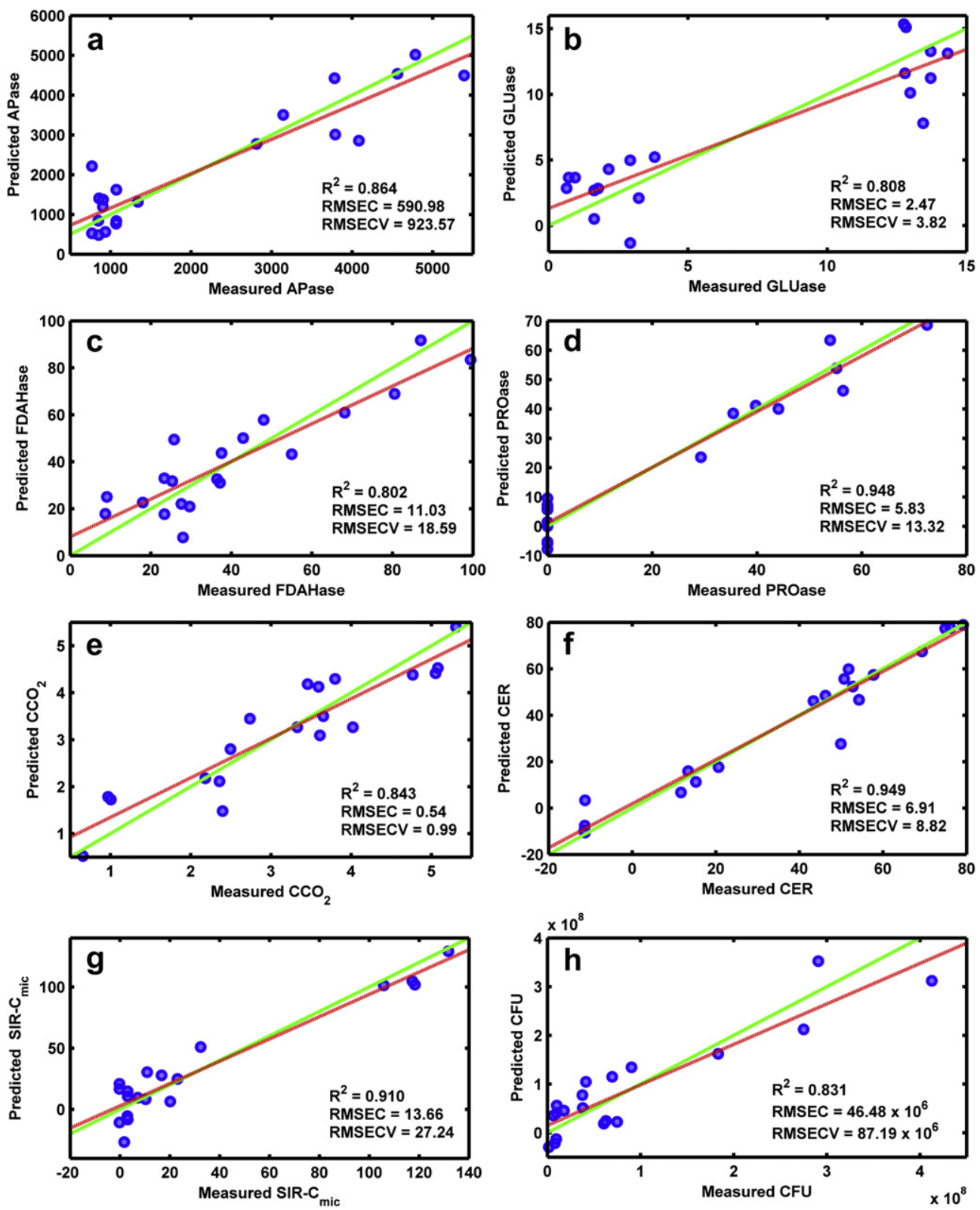

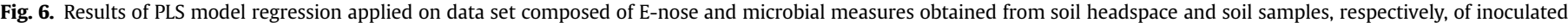

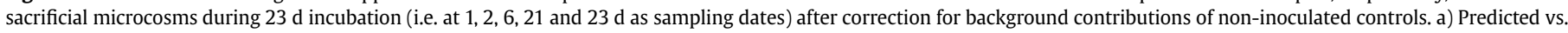

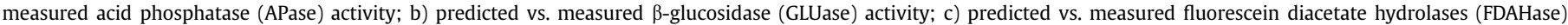

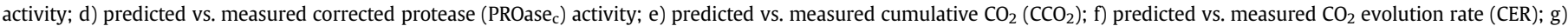

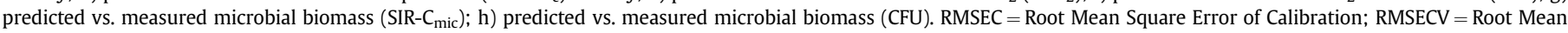

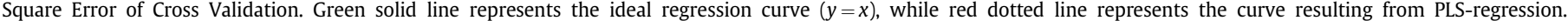
(For interpretation of the references to colour in this figure legend, the reader is referred to the web version of this article.)

where SIR- $\mathrm{C}_{\text {mic }}$ and $\mathrm{CCO}_{2}$ became the most discriminant with respect to the previous phases, additionally to the activity of GLUase and PROase ${ }_{c}$, thus further supporting the hypothesis of priming effect occurrence (where the production of $\mathrm{CO}_{2}$ and the activities of GLUase or other cellulose-degrading enzymes, PROases and oxidoreductases involved in lignin degradation have also been reported as good indicators for identification of such a process) (Kuzyakov et al., 2000; Blagodatskaya et al., 2007). During this event, in fact, microorganisms obtain nutrients for their maintenance and growth by SOM mineralisation to $\mathrm{CO}_{2}$, which adds to that one evolved from soil by microbial basal respiration, only (Kuzyakov et al., 2000; Kuzyakov, 2006). In the present study, the nutrient can actually become limiting since $0.16 \mu \mathrm{g}$ glucose-C supplied to soil at $T_{0}$ was much lower than the sum of $\mathrm{CCO}_{2}$ and SIR- $C_{\text {mic }}$ (i.e. $1.42 \mu \mathrm{g} \mathrm{C}$ ) of inoculated soil microcosms at $6 \mathrm{~d}$. From 6 to $21 \mathrm{~d}$ of incubation the bacterial population started experiencing starvation till a proper resting or even death phase, where the main distinctive factor was $\mathrm{CCO}_{2}$, but after the second nutritive supply a renewed exponential growth was observed, where the effect due mainly to FDHase activity and CFU, and at a lower extent to $\mathrm{CO}_{2}$ SIR- $\mathrm{C}_{\mathrm{mic}}^{-1}$ prevailed. The existence of all such relationships between enzyme activities and physiological and growth phases of the bacterial population also gave some clues about the fate of substrates degraded by these enzymes, i.e. that the products of catalyses were further transformed (involving also the possible production of VOCs) up to mineralisation $\left(\mathrm{CO}_{2}, \mathrm{NH}_{3}\right.$, etc.). The 
resulting image of the microbial measures processed through multivariate analysis can effectively represent a complex microbial fingerprint of the whole gnotobiotic and axenic soil ecosystem tested in this study, which is able to provide a holistic representation of both the biochemical and microbiological features of soils as described by Nannipieri et al. (2002) and Hinojosa et al. (2004), and that can reasonably reflect, indeed, a proper metabolic fingerprint. By integrating the resulting dynamics of different parameters, in fact, the occurrence of complex metabolic processes may be suggested. Additional to the link of the above cited GLUase, PROa$\mathrm{se}_{\mathrm{c}}, \mathrm{CCO}_{2}$ and SIR- $\mathrm{C}_{\mathrm{mic}}$ to the priming effect, in fact, also the dynamics of APase and PROasec activities might be linked to alternative aerobic and anaerobic conditions and well known $\mathrm{pH}$ decrease, upon $\mathrm{CO}_{2}$ increase (Nobel and Palta, 1989), which can affect $P_{i}$ availability (Wentzel et al., 1991; Lemos et al., 1998), or to $\mathrm{NH}_{4}^{+}$dynamics (absorption and fixation), upon the contemporary supply of $\mathrm{NH}_{4}^{+}$and glucose (Vega-Jarquin et al., 2003; Conde et al., 2005), respectively.

The E-nose responses analysed through PCA and PLS-DA, showed that they too could be grouped into distinct clusters (on a multivariate basis) (i.e. the olfactory fingerprint) (Pearce et al., 2003) reflecting, in this case, the classification of soil microcosms into increasing incubation periods, and then into different growth and metabolic phases of the bacterial population (on a biochemical and microbiological basis combined to a multivariate basis). It is noteworthy, that although the values of both respiration parameters tested $\left(\mathrm{CCO}_{2}\right.$ and $\left.\mathrm{CER}\right)$ did not show any significant difference during similar exponential growth phases occurring within $48 \mathrm{~h}$ after both nutrient supplies (i.e. $2 \mathrm{~d}$ and $23 \mathrm{~d}$ ), the microbial activity of the two soil ecosystems analysed on a multivariate basis from biochemical parameters pointed out differences between these two sampling dates. The detection of soil enzyme activities at these dates, in fact, showed the presence of different metabolic processes, as well as differences were observed for $\mathrm{CO}_{2}$ SIR- $\mathrm{C}_{\text {mic }}^{-1}$. Interestingly, also the E-nose was capable of detecting such a difference. Hence, the E-nose is a more reliable tool to detect microbial activity in soil than determination of respiration only, as well as the multivariate analysis of soil based on several biochemical parameters, since it can perceive not only the $\mathrm{CO}_{2}$ released by microorganisms during their growth phases, but also further substances derived from other metabolic processes. Such similarities between the multivariate analysis applied to biochemical and microbiological parameters and that applied to E-nose responses was confirmed by the supervised PLS-regression analysis carried out on both kinds of data set together, once corrected for background contributions of non-inoculated controls, which demonstrated that these two groups of measures matched reciprocally and were strongly related each other $\left(0.802<R^{2}<0.949\right)$. Such strong relationships suggest that, at least in the gnotobiotic and axenic conditions here used, E-nose technology is actually capable of detecting bacterial metabolic activities associated with both substrate degradation (respiration) and mobilisation of nutrients (mainly APase, GLUase and FDAHase activities). Under a sensory point of view, it is noteworthy that a "specific sensor array", i.e. where each sensor detects a specific metabolic activity, as the group of biochemical and microbiological parameters can be considered when used in the multivariate analysis, might be closely related to an "unspecific sensor array", such as the E-nose is, i.e. where each sensor commonly responds "unspecifically" (Pearce et al., 2003). Hence, on the base firstly of the relationships between hydrolytic activities and respiration or the reasonable release of other gases and/or VOCs previously mentioned, and secondly of the strong relationships between the measures of microbial parameters and E-nose, it resulted to be insubstantial also the questionable point whether biochemical parameters, associated with bacterial metabolism and whose catalytic products are not properly VOCs or gases, might somehow contribute to the release of VOCs and/or gases detectable by the E-nose. A reasonable explanation for this result, in fact, may be that the biochemical activities tested here either induced or took part to more complex metabolic pathways (respiration, substrate degradation and mineralisation, nitrification/denitrification, etc.) that somehow resulted in production of VOCs and/or gases.

In the present study, E-nose measurements performed in sterilised non-inoculated soil microcosms also showed that the headspace of these samples changed over time. Such a finding might arise some questions about the possible reasons for this event. However, in one of the previous studies where E-nose technology was applied to soil, instead, no specific measurement was carried out on sterilised soil to assess possible modifications in VOCs and/or gases released into the headspace of abiotic controls by the soil matrix (Bastos and Magan, 2007). Since the only difference between inoculated and control microcosms was the presence of bacteria, it is presumable that such changes in headspace of non-inoculated soil microcosms should be related to unspecific (abiotic) processes resulting in the release of volatiles and/or gases. Volatile organic compounds in soil are commonly present in SOM and are comprised of low-molecular weight aromatic compounds, while gases are commonly adsorbed onto soil particle surface. Warneke et al. (1999) reported in fact, the emission of acetone, methanol and other partially oxidised organic compounds from decomposing litter upon abiotic processes. The presence of very small litter fragments even after sieving was observable, in fact, in the present soil samples. Further possible abiotic processes occurring also in control microcosms in the experimental conditions here used can affect the behaviour of VOCs and/or gases, such as adsorption/desorption/volatilisation cycles depending on temperature and on variations in soil water content upon evaporation processes, which could affect the diffusion of such compounds into headspace by varying the availability of soil pores to gas exchange. The $30^{\circ} \mathrm{C}$ incubation temperature here used could induce such processes over time in control microcosms as well, thus determining progressive changes in headspace. The evaporation process was confirmed by the presence of condensed water vapour on the glass vessels of soil microcosms. Such abiotic modifications of microcosm headspace could be additional to the release of biogenic analytes by bacterial metabolism (inoculated ecosystems) stimulated by nutrient addition. Incidentally, the occurrence of background contributions of control samples to the values of detected parameters is a common situation in every assay in soil studies, whatever the techniques used to detect a parameter (from spectrometry to chromatography, electrochemistry, etc.). Especially in soil samples, several interfering factors are present and controls need to be carefully prepared and measured to evaluate the actual values of parameters of interest in samples. Similarly, when E-nose technology is applied to soil samples, the measurement of control samples contributes to correctly evaluate the actual values of samples. The fact that non-inoculated microcosms measured through the E-nose showed greater differences with respect to distinct incubation periods than relative to the inoculated microcosms at the same sampling dates suggests that abiotic processes such as gas exchange and diffusion and all other abiotic factors that can affect such processes were pivotal discriminants in E-nose detection of analytes in soil samples over time, with respect even to the biogenic production of VOCs and/or gases by microorganisms only. Since these abiotic processes govern the release of VOCs and/or gases into headspace of both controls and inoculated soil microcosms, such result can be reasonably expected. Notwithstanding such premises, the statistical difference between control and inoculated microcosms measured through the E-nose was assessed and confirmed, through the various 
multivariate analyses here used, thus validating the reliability of E-nose technology to measure the microbial activity in soil, despite the high contribution of abiotic samples (non-incubated controls). The fact that microbial parameters pointed out marked differences between control and inoculated microcosms while in E-nose responses such differences were not so conspicuous is apparent and is inherent to the specific procedures performed in the measurements. In microbial parameter detection, in fact, the abiotic contribution of soil (e.g. chromophore release) had been already subtracted from all samples, both control and inoculated samples, to reckon the measures. Then, the final values relative to control samples will approximated necessarily to zero, except for those parameters, such as APase and PROase activities, where not only an abiotic contribution was present but also a biotic one, although it was independent from the presence of microbes (immobilised enzymes (Burns, 1982)) and resulted only partially inhibited by nutrients (PROase activity). This is not the case for E-nose responses, where the contribution of possible abiotic processes was not subtracted from sensory readouts of both control and inoculated samples, except when PLS-regression was carried out (Fig. 6). Additionally, several studies have demonstrated that in unsterilised soil samples, the microbial population reduce the amount of VOCs in headspace, which are used as substrates (Asensio et al., 2007; Ramirez et al., 2010), and this event might contribute to reduce the differences between control and inoculated microcosms. Hence, the application of E-nose technology to soil science, at least in the conditions used in this study, can result to be an easy tool to measure microbial activity in soil comparable to the multivariate analysis applied to several biochemical and microbiological parameters measurements. Furthermore, the E-nose is able to supply information similar (on a quality basis, at least) to those obtained through a multivariate analysis applied to several microbial measurements, as proposed in recent studies (Nannipieri et al., 2002; Hinojosa et al., 2004; Acosta-Martinez et al. 2003), by carrying out only one measurement per sample. Hence, it is evident the advantage in the use of E-nose technology with respect to other common methodologies. However, the main disadvantage of such a technique is generally to supply qualitative measures instead of quantitative, as soil scientists are used to obtain from measurements they usually carry out, instead, but some solutions to such a disadvantage will be discussed in the next sub-section. Interestingly, E-nose responses were highly related not only to soil microbial activity but also to the quantity of living and active bacteria in soil ecosystems, both measured as SIR- $C_{m i c}$ and $\mathrm{CFU}$

\subsection{Perspectives in sensing soil ecosystems}

In this study the capability of the E-nose technology of measuring microbial activity in soil was assessed and verified. Furthermore, the E-nose technology enables comprehensive measurements of the whole soil ecosystem. As a matter of fact, as the measurements of non-inoculated microcosms have demonstrated in this study, the E-nose technology enables soil scientists to detect volatiles and/or gases not only of biogenic origin, but also released from abiotic components of soil and generated by abiotic processes (e.g. adsorption/desorption/volatilisation processes, evaporation, etc.). This event, which could theoretically be perceived by soil scientists as an awful feature, might be instead an improvement for researchers, with respect to other techniques (e.g. GC-MS, etc.). As a matter of fact, once the scientists have performed suitable control samples (e.g. sterile samples), as it is required by all kinds of parameters commonly tested in soil, and they have measured the relative headspace through the E-nose in order to identify the contribution of controls, the information they can obtain by applying such a technology can involve all the aspects in soil ecosystems related to the presence of microorganism, whatever the number of species there present. Hence, not only VOCs and/or gases strictly related to single biochemical activities or complex metabolisms expressed by different microbial species can be detected, but also compounds released into headspace as a consequence of modifications of the environments due to microbial activities in soil ecosystems (e.g. VOCs release upon biogenic increase of temperature, $\mathrm{CO}_{2}$ released upon of weathering of carbonates induced by biogenic $\mathrm{pH}$ decrease, etc.). This latter event, for example, could be easily demonstrated by measuring the headspace of sterile carbonate-containing soil samples upon addition of acidic solutions.

As concerns the detection of biogenic VOCs and/or gases, instead, the E-nose technology permits also comprehensive measurements of all metabolic activities occurring in soil ecosystems that can somehow determine a release of such analytes into sample headspace, even those that are still unknown. Differently, any kind of multivariate analysis carried out on microbial parameters measured separately cannot provide similar information, as a consequence of the obvious restrictions due not only to the finite time that researchers can devote to a single study, but also to the limitation in the knowledge of metabolic pathways. However, there are other techniques that are able to supply a fingerprint of sample headspace, although they are more expensive and time-consuming, and often require complex preparations of samples (extractions through solid phase extraction or solid phase microextraction) and specific chromatographic processing (gas-chromatographers - GC, etc.) and detectors (mass spectrometers - MS) (Curran et al., 2005; De Cesare et al., 2008), although some improvements have been achieved with Proton-Transfer-Reaction-MS (Lindinger et al., 1998). The advantage of these latter techniques is mainly to supply quantification of compounds detected and composing the fingerprints, while the E-nose mainly supply qualitative measures, except when such a device is adequately calibrated and trained (De Cesare et al., 2009). However, even in studies where the techniques mentioned above are used, several peaks cannot be often ascribed to specific substances. In the E-nose technology, instead, where one of the basic principles is the low specificity of sensors, despite their high selectivity, so that several substances can be detected at the same time, all volatiles and/or gases present in sample headspace or most of them can be measured (according to the selected coatings used), in principle. In any case, the actual meaning of the olfactory fingerprint resulting from the E-nose responses of soil ecosystems is not a poor list of compounds derived from several and even unknown metabolic activities, but the concurrent perception of different substances, where analytes can interact, compete or combine, thus contributing to the stimulation of the global responses by the E-nose. Such olfactory fingerprint then reproduces the entire ecosystem as perceived by any living organisms in the ecosystem, as well as we smell the environment where we live, and then it might represent a real holistic measure of soil ecosystems. This feature is the main and very promising potential, indeed, in the application of the E-nose technology to complex ecosystems such as soil, which can even get beyond its specific use for microbial activity detection, as reported in this study. It is also noteworthy that the E-nose, regardless of the specific experimental plan used in this study, is able to measure environments causing very low disturbance during sampling and measurement, thus making results more reliable and closer to the effective natural values. As a consequence, this approach is further noticeable because it is less time-consuming than several traditional techniques, since information about the whole ecosystem can be obtained with just one series of measurements (replicates). The evident usefulness of the E-nose technology for 
the measurement of metabolic activity in soil ecosystems resulting from the considerations above, suggest that this technology can be proposed not only as an additional technique to the traditional ones, but also as an alternative methodology, under specific experimental conditions or when scientists are interested to get overall information on the whole soil ecosystem in natural conditions.

\section{Conclusions}

This is the first study, to our knowledge, about the specific use of an electronic nose to measure soil microbial activity. The experimental plan involved the incubation of sterilised soil microcosms inoculated with $P$. fluorescens for a period of time after nutritive inputs, the quantification of microbial population and of its metabolic activity, and the detection and monitoring of the release of VOCs and/or gases in soil microcosm headspace through the alternating physiological conditions and growth phases of the bacterial population (exponential, stationary and resting or death phases) over the incubation period. The multivariate analyses applied to both microbial and E-nose measures showed that it was possible to discriminate between inoculated and control microcosms, despite the evolution occurring also in control headspace over time and that microbial measures and sensor readouts were strongly and positively correlated, then suggesting that the E-nose was capable of recognising the substances specifically derived from microbial metabolism, generating an olfactory fingerprint that actually reflected the metabolic fingerprint typical of the whole gnotobiotic and axenic soil ecosystem under study. Such findings further support that the E-nose technology can be successfully used in monitoring soil ecosystems in natural and perturbed conditions (pollution contamination, bioremediation, soil fertility, etc.) (De Cesare et al., 2008) additionally to commonly used traditional analytical methods.

\section{Acknowledgements}

The authors wish to thank, for their kind support to this study, Dr. G. Angelini of the Institute of Chemical Methodologies, National Research Council, Montelibretti, Rome (Italy), for $\gamma$-irradiation of soil used in the experiments and Mr. G. Ubertini of the Department of Crop Production, University of Tuscia, Viterbo (Italy), for measurements of $\mathrm{N}_{\text {tot }}, \mathrm{C}_{\text {org }}$ and soil texture.

\section{References}

Acosta-Martinez, V., Zobeck, T.M., Gill, T.E., Kennedy, A.C., 2003. Enzyme activities and microbial community structure in semiarid agricultural soils. Biology and Fertility of Soils 38, 216-227.

Allen, A.S., Schlesinger, W.H., 2004. Nutrient limitations to soil microbial biomass and activity in loblolly pine forests. Soil Biology and Biochemistry 36, 581-589.

Anderson, J.P.E., Domsch, K.H., 1978. A physiological method for quantitative measurement of microbial biomass in soils. Soil Biology and Biochemistry 10, 215-221.

Asensio, D., Penuelas, J., Filella, I., Llusia, J., 2007. On-line screening of soil VOCs exchange responses to moisture, temperature and root presence. Plant and Soil 291, 249-261.

Bååth, E., Diaz-Raviña, M., Bakken, L.R., 2005. Microbial biomass, community structure and metal tolerance of a naturally Pb-enriched forest soil. Microbial Ecology 50, 496-505.

Bailey, V.l., Bolton Jr., H., Smith, J.L., 2008. Substrate-induced respiration and selective inhibition as measures of microbial biomass in soils. In: Carter, M.R., Gregorich, E.G. (Eds.), Soil Sampling and Methods of Analysis, second ed. CRC Press - Taylor \& Francis Group, Boca Raton, pp. 515-526.

Bastos, A.C., Magan, N., 2007. Soil volatile fingerprints: use for discrimination between soil types under different environmental conditions. Sensors and Actuators B: Chemical 125, 556-562.

Blagodatskaya, E.V., Blagodatsky, S.A., Anderson, T.-H., Kuzyakov, Y., 2007. Priming effects in Chernozem induced by glucose and $\mathrm{N}$ in relation to microbial growth strategies. Applied Soil Ecology 37, 95-105.
Blagodatskaya, E.V., Kuzyakov, Y., 2008. Mechanisms of real and apparent priming effects and their dependence on soil microbial biomass and community structure: critical review. Biology and Fertility of Soils 45, 115-131.

Brookes, P.C., Cayuela, M.L., Contin, M., De Nobili, M., Kemmitt, S.J., Mondini, C., 2008. The mineralisation of fresh and humified soil organic matter by the soil microbial biomass. Waste Management 28, 716-722.

Burns, R.G., 1982. Enzyme activity in soil: location and a possible role in microbial ecology. Soil Biology and Biochemistry 14, 423-427.

Conde, E., Cardenas, M., Ponce-Mendoza, A., Luna-Guido, M.L., Cruz-Mondragon, C., Dendooven, L., 2005. The impact of inorganic nitrogen application on mineralization of ${ }^{14} \mathrm{C}$-labelled maize and glucose, and on priming effect in saline alkaline soil. Soil Biology and Biochemistry 37, 681-691.

Conrad, R., 1996. Soil microorganisms as controllers of atmospheric trace gases $\left(\mathrm{H}_{2}, \mathrm{CO}_{2}, \mathrm{CH}_{4}, \mathrm{OCS}, \mathrm{N}_{2} \mathrm{O}\right.$, and NO). Microbiological Reviews 60, 609-640.

Curran, A.M., Rabin, S.I., Prada, P.A., Furton, K.G., 2005. Comparison of the volatile organic compounds present in human odor using SPME-GC/MS. Journal of Chemical Ecology 31, 1607-1619.

Davidson, E.A., Verchot, L.V., Cattanio, J.H., Ackerman, I.L., Carvalho, J.E.M., 2000. Effects of soil water content on soil pastures of eastern Amazonia. Biogeochemistry 48, 53-69.

De Cesare, F., Pantalei, S., Zampetti, E., Macagnano, A., 2008. Electronic nose and SPME techniques to monitor phenanthrene biodegradation in soil. Sensors and Actuators B: Chemical 131, 63-70.

De Cesare, F., Zampetti, E., Pantalei, S., Magagnano, A., 2009. Comparison between sensing systems for ammonium detection and measurement in soil. In: Pardo, M., Sberveglieri, G. (Eds.), Olfaction and Electronic Nose: Proceedings of the 13th International Symposium on Olfaction and Electronic Nose, Brescia, Italy, 15-17 April 2009, AIP Conference Proceedings, vol. 1137. American Institute of Physics, Melville, pp. 461-464.

de la Paz Jimenez, M., de la Horra, A.M., Pruzzo, L., Palma, R.M., 2002. Soil quality: a new index based on microbiological and biochemical parameters. Biology and Fertility of Soils 35, 302-306.

De Nobili, M., Contin, M., Mondini, C., Brookes, P.C., 2001. Soil microbial biomass is triggered into activity by trace amounts of substrate. Soil Biology and Biochemistry 33, 1163-1170.

Di Mattia, E., Grego, S., Cacciari, I., 2002. Eco-physiological characterization of soil bacterial populations in different states of growth. Microbial Ecology 43, 34-43.

Di Natale, C., Paolesse, R., Macagnano, A., Nardis, S., Martinelli, E., Dalcanale, E. Costa, M., D’Amico, A., 2004. Sensitivity-selectivity balance in mass sensors: the case of metalloporphyrins. Journal of Materials Chemistry 14, 1281-1287.

Dick, R.P., 1997. Soil enzyme activities as integrative indicators of soil health. In: Pankhurst, C.E., Doube, B.M., Gupta, V.V.S.R. (Eds.), Biological Indicators of Soil Health. CAB International, Wallingford, pp. 121-156.

Dick, R.P., Breakwell, D.P., Turco, R.F., 1996. Soil enzyme activities and biodiversity measurements as integrative microbiological indicators. In: Doran, J.W. Jones, A.J. (Eds.), Methods for Assessing Soil Quality. SSSA Special Publication Number 49. Soil Science Society of America, Madison, pp. 247-272.

Dijkhuizen, L., Harder, W., 1985. Microbial metabolism of carbon dioxide. In: Bull, A., Dalton, H. (Eds.), Comprehensive Biotechnology. Pergammon Press, Oxford, pp. 409-423.

Fernando, W.G.D., Ramarathnam, R., Krishnamoorthy, A.S., Savchuk, S.C., 2005. Identification and use of potential bacterial organic antifungal volatiles in biocontrol. Soil Biology and Biochemistry 37, 955-964.

Gibson, T.D., Prosser, O., Hulbent, J.N., Marshall, R.W., Corcoran, P., Lowery, P., RuckKeen, E.A., Heron, S., 1997. Detection and simultaneous identification of microorganisms from headspace samples using an electronic nose. Sensors and Actuators B: Chemical 44, 413-422.

Grate, J., Abraham, M., 1991. Solubility interactions and the design of chemically selective sorbent coatings for chemical sensors and arrays. Sensors and Actuators B: Chemical 3, 85-111.

Green, V.S., Stott, D.E., Diack, M., 2006. Assay for fluorescein diacetate hydrolytic activity: optimization for soil samples. Soil Biology and Biochemistry 38 , 693-701.

He, Z.L., Yang, X.E., Baligar, V.C., Calvert, D.V., 2003. Microbiological and biochemical indexing systems for assessing quality of acid soils. Advances in Agronomy 78, 89-138.

Hesselsoe, M., Nielsen, J.L., Roslev, P., Nielsen, P.H., 2005. Isotope labelling and microautoradiography of active heterotrophic bacteria on the basis of assimilation of ${ }^{14} \mathrm{CO}_{2}$. Applied and Environmental Microbiology 71, 646-655.

Hinojosa, M.B., Carreira, J.A., Garcia-Ruiz, R., Dick, R.P., 2004. Soil moisture pretreatment effects on enzyme activities as indicators of heavy metalcontaminated and reclaimed soils. Soil Biology and Biochemistry 36, 1559-1568.

Höper, H., 2006. Substrate-induced respiration. In: Bloem, J., Hopkins, D.W., Benedetti, A. (Eds.), Microbiological Methods for Assessing Soil Quality. CABI Publishing, Wallingford, pp. 84-92.

Jenkinson, D.S., Pawlson, D.S., 1976. The effects of biocidal treatments on metabolism in soil - V. A method for measuring soil biomass. Soil Biology and Biochemistry 8, 209-213.

Kai, M., Hausteiner, M., Molina, F., Petri, A., Scholz, B., Piechulla, B., 2009. Bacterial volatiles and their action potential. Applied Microbiology and Biotechnology 81, 1001-1012.

Kornbeg, H.L., 1966. Anaplerotic sequences and their role in metabolism. In: Campbell, P.-N., Greville, G.D. (Eds.), Essays in Biochemistry, vol. 2. Academic Press, London, pp. 1-31. 
Kurup, P.U., Issac, B., Griffin, E.P., 2006. Electronic nose-membrane interface probe for geoenvironmental site characterization. Journal of Geotechnical and Geoenvironmental Engineering 132, 1133-1142.

Kuzyakov, Y., 2006. Sources of $\mathrm{CO}_{2}$ efflux from soil and review of partitioning methods. Soil Biology and Biochemistry 38, 425-448.

Kuzyakov, Y., Friedel, J.K., Stahr, K., 2000. Review of mechanisms and quantification of priming effects. Soil Biology and Biochemistry 32, 1485-1498.

Ladd, J.N., Butler, J.H.A., 1972. Short-term assays of soil proteolytic enzyme activities using proteins and peptide derivatives as substrates. Soil Biology and Biochemistry 4, 19-30.

Lee, Y.B., Lorenz, N., Dick, L.K., Dick, R.P., 2007. Cold storage and pre-treatment incubation effects on soil microbial properties. Soil Science Society of America Journal 71, 1299-1305.

Leff, J.W., Fierer, N., 2008. Volatile organic compound (VOC) emissions from soil and litter samples. Soil Biology and Biochemistry 40, 1629-1636.

Lemos, P.C, Viana, C, Salgueiro, EN Ramos, A.M Crespo, JPS.G, Reis, M.A.M. 1998. Effect of carbon source on the formation of polyhydroxyalkanoates (PHA) by a phosphate-accumulating mixed culture. Enzyme and Microbial Technology $22,662-671$

Lindinger, W., Ansel, A., Jordan, A., 1998. On-line monitoring of volatile organic compounds at pptv levels by means of Proton-Transfer-Reaction Mass Spectrometry (PTR-MS) Medical applications, food control and environmental research. International Journal of Mass Spectrometry and Ion Processes 173, 191-241.

Linn, D.M., Doran, J.W., 1984. Effect of water-filled pore space on carbon dioxide and nitrous oxide production in tilled and nontilled soils. Soil Science Society of America Journal 48, 1267-1272.

Lotti, G., Galoppini, C., 1980. Guida alle analisi chimico-agrarie: esercitazioni di chimica analitica, industrie agrarie e chimica agraria, second ed. Edagricole Bologna, $434 \mathrm{pp}$.

Lucklum, R., Henning, B., Hauptmann, P., Schierbaum, K.D., Vaihinger, S., Göpel, W., 1991. Quartz microbalance sensors for gas detection. Sensors and Actuators A: Physical 25-27, 705-710.

Margesin, R., Zimmerbauer, A., Schinner, F., 2000. Monitoring of bioremediation by soil biological activities. Chemosphere 40, 339-346.

Mascher, T., Zähner, M., Merai, M., Balmelle, N., de Saizieu, A.B., Hakenbeck, R., 2003. The Streptococcus pneumoniae cia regulon: CiaR target sites and transcription profile analysis. Journal of Bacteriology 185, 60-70.

McEntegart, C.M., Penrose, W.R., Strathmann, S., Stetter, J.R., 2000. Detection and discrimination of coliform bacteria with gas sensor arrays. Sensors and Actuators B: Chemical 70, 170-176.

McNeal, K.S., Herbert, B.E., 2009. Volatile organic metabolites as indicators of soil microbial activity and community composition shifts. Soil Science Society of America Journal 73, 579-588.

Miltner, A., Richnow, H.-H., Kopinke, F.-D., Kästner, M., 2004. Assimilation of $\mathrm{CO}_{2}$ by soil microorganisms and transformation into soil organic matter. Organic Geochemistry 35, 1015-1024.

Nannipieri, P., Grego, S., Ceccanti, B., 1990. Ecological significance of the biologica activity in soil. In: Bollag, J.-M., Stotzky, G. (Eds.), Soil Biochemistry, vol. 6. Marcel Dekker, Inc., New York, pp. 293-355.

Nannipieri, P., Kandeler, E., Ruggiero, P., 2002. Enzyme activities and microbiologica and biochemical processes in soil. In: Burns, R.G., Dick, R.P. (Eds.), Enzymes in the Environment - Activity, Ecology, and Applications. Marcel Dekker, Inc., New York, pp. 1-33.

Nobel, P.S., Palta, J.A., 1989. Soil $\mathrm{O}_{2}$ and $\mathrm{CO}_{2}$ effects of root respiration of cacti. Plant and Soil 120, 263-271.

Orchard, V.A., Cook, F.J., 1983. Relationship between soil respiration and soil moisture. Soil Biology and Biochemistry 15, 447-453.

Pankhurst, C.E., 1994. Biological indicators of soil health and sustainable productivity. In: Greenland, D.J., Szabolcs, I. (Eds.), Soil Resilience and Sustainable Land Use. CAB International, Wallingford, pp. 331-351.
Pearce, T.C., Schiffman, S.S., Nagle, H.T., Gardner, J.W., 2003. Handbook of Machine Olfaction - Electronic Nose Technology. Wiley-WCH Verlag GmbH, Darmstadt, 624 pp.

Perez, R.C., Matin, A., 1982. Carbon dioxide assimilation by Thiobacillus novellus under nutrient-limited tixotrophic conditions. Journal of Bacteriology 150, 46-51.

Persaud, K.C., Khaffaf, S.M., Payne, J.S., Pisanelli, A.M., Lee, D.-H., Byun, H.-G., 1996 Sensor array techniques for mimicking the mammalian olfactory system. Sensors and Actuators B: Chemical 36, 267-273.

Ramirez, K.S., Lauber, C.L., Fierer, N., 2010. Microbial consumption and production of volatile organic compounds at the soil-litter interface. Biogeochemistry 99, 97-107.

Ravnskov, S., Jakobsen, I., 1999. Effects of Pseudomonas fluorescens DF57 on growth and $P$ uptake of two arbuscular mycorrhizal fungi in symbiosis with cucumber. Mycorrhiza 8, 329-334.

Renella, G., Szukics, U., Landi, L., Nannipieri, P., 2007. Quantitative assessment of hydrolase production and persistence in soil. Biology and Fertility of Soils 44, 321-329.

Santruckova, H., Bird, M.I., Elhottova, D., Novak, J., Picek, T., Simek, M., Tykva, R., 2005. Heterotrophic fixation of $\mathrm{CO}_{2}$ in soil. Microbial Ecology 49, 218-225.

Schnürer, J., Rosswall, T., 1982. Fluorescein diacetate hydrolyse as a measure of total microbial activity in soil and litter. Applied and Environmental Microbiology 43, 1256-1261.

Shaw, L.J., Burns, R.G., 2006. Enzyme activity profiles and soil quality. In: Bloem, J., Hopkins, D.W., Benedetti, A. (Eds.), Microbiological Methods for Assessing Soil Quality. CABI Publishing, Wallingford, pp. 158-182.

Sheppard, S.K., Loyd, D., 2002. Direct mass spectrometric measurement of gases in soil monoliths. Journal of Microbiological Methods 50, 175-188.

Smolander, A., Ketola, R.A., Kotiaho, T., Kanerva, S., Suominenen, K., Kitunen, V., 2006. Volatile monoterpenes in soil atmosphere under birch and conifers: effects on soil N transformations. Soil Biology and Biochemistry 38, 3436-3442.

Smolander, A., Kurka, A., Kitunen, V., Mälkönen, E., 1994. Mirobial biomass C and N, and respiratory activity in soil of repeatedly limed and N- and P-fertilized Norway spruce stands. Soil Biology and Biochemistry 26, 957-962.

Tabatabai, A., 1994. Soil enzymes. In: Weaver, R.W., Angle, S., Bottomley, P. (Eds.), Methods of Soil Analysis. Part 2. Microbiological and Biochemical Properties. SSSA Book Series No 5. Soil Science Society of America, Madison, pp. 775-834.

Taylor, J.P., Wilson, B., Mills, M.S., Burns, R.G., 2002. Comparison of microbial numbers and enzymatic activities in surface soils and subsoils using various techniques. Soil Biology and Biochemistry 34, 387-401.

Thorn, R.M.S., Reynolds, D.M., Greenman, J., 2011. Multivariate analysis of bacterial volatile compound profiles for discrimination between selected species and strains in vitro. Journal of Microbiological Methods 84, 258-264.

Vance, E.D., Nadkarni, N.M., 1990. Microbial biomass and activity in canopy organic matter and the forest floor of a tropical cloud forest. Soil Biology and Biochemistry 22, 677-684.

Vance, E.D., Brooks, P.C., Jenkinson, D.S., 1987. An extraction method for measuring soil microbial biomass C. Soil Biology and Biochemistry 19, 703-707.

Vega-Jarquin, C., Garcia-Mendoza, M., Jablonowski, N., Luna-Guido, M., Dendooven, L. 2003. Rapid immobilization of applied nitrogen in saline-alkaline soils. Plant and Soil 256, 379-388.

Violante, P. (Ed.), 2000. Metodi di Analisi Chimica del Suolo. Franco Angeli, Milano, $536 \mathrm{pp}$.

Warneke, C., Karl, T., Judmaier, H., Hansel, A., Jordan, A., Lindinger, W., Crutzen, P.J., 1999. Acetone, methanol, and other partially oxidized volatile organic emissions from dead plant matter by a biological processes: significance for atmospheric HOx chemistry. Global Biogeochemical Cycles 13, 9-17.

Wentzel, M.C., Lötter, L.H., Ekama, G.A., Loewenthal, R.E., Marais, G.V.R., 1991 Evaluation of biochemical models for biological excess phosphorus removal. Water Science Technology 23, 567-576.

Wood, H.G., Werkman, C.H., 1936. The utilization of $\mathrm{CO}_{2}$ in the dissimilation of glycerol by propionic acid bacteria. Biochemical Journal 30, 48-53. 